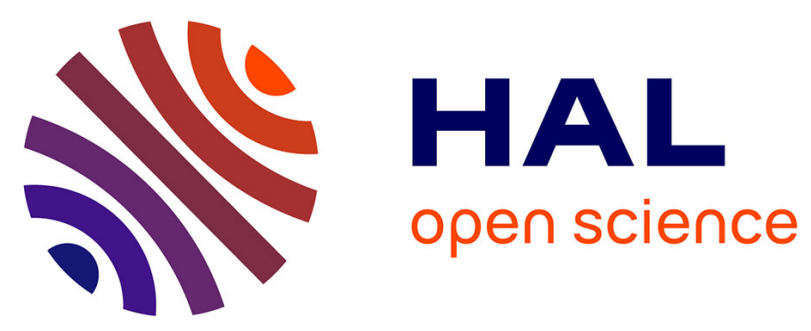

\title{
New insight into the cold crystallization of natural rubber: The role of linked and free fatty chains
}

\author{
Jérémie Grangé, Alexei Radchenko, Rachid Matmour, François
}

Jean-Baptiste-Dit-Dominique, Stéphane Grelier, Frédéric Peruch

\section{- To cite this version:}

Jérémie Grangé, Alexei Radchenko, Rachid Matmour, François Jean-Baptiste-Dit-Dominique, Stéphane Grelier, et al.. New insight into the cold crystallization of natural rubber: The role of linked and free fatty chains. Polymer Crystallization, 2019, 2 (4), pp.e10075. 10.1002/pcr2.10075 . hal-02352797

\section{HAL Id: hal-02352797 \\ https://hal.science/hal-02352797}

Submitted on 24 Sep 2020

HAL is a multi-disciplinary open access archive for the deposit and dissemination of scientific research documents, whether they are published or not. The documents may come from teaching and research institutions in France or abroad, or from public or private research centers.
L'archive ouverte pluridisciplinaire HAL, est destinée au dépôt et à la diffusion de documents scientifiques de niveau recherche, publiés ou non, émanant des établissements d'enseignement et de recherche français ou étrangers, des laboratoires publics ou privés. 
DOI: 10.1002/marc.((insert number)) ((or ppap., mabi., macp., mame., mren., mats.))

\section{Article Type: Full Paper}

\section{New Insight into the Cold Crystallization of Natural Rubber: The Role of Linked and Free Fatty Chains}

Jérémie Grange ${ }^{\mathrm{a}, \mathrm{b}}$, Alexei V. Radchenko ${ }^{\mathrm{a}}$, Rachid Matmour ${ }^{\mathrm{b}}$, François Jean-Baptiste dit Dominique ${ }^{\mathrm{b}}$, Stéphane Grelier ${ }^{\mathrm{a}}$, Frédéric Peruch ${ }^{\mathrm{a}}$ *

${ }^{a}$ Univ. Bordeaux, CNRS, Bordeaux INP, LCPO, UMR 5629, F-33600, Pessac, France

${ }^{\mathrm{b}}$ Manufacture Française des Pneumatiques Michelin, Z.I. Ladoux, F-63040 Clermont-Ferrand Cedex 9, France

*E-mail: peruch@enscbp.fr

ABSTRACT: Natural Rubber (NR) is a polyisoprene (PI) from renewable resources that exhibits mechanical and thermal properties not accessible with synthetic polyisoprenes (IR). In this article, it was developed a simple route to synthesize new models of NR (PI with a pure microstructure (100\% 1,4-cis) and two fatty esters linked to the polymer chain-end) in order to clarify the role played by lipids on the "cold crystallization" (CCr) of NR. DSC analysis of this new hybrid polymer revealed that the lipids linked to the backbone were able to crystallize despite of the amorphous matrix, the crystallization temperature being dependent on the length of the linked fatty chain. Furthermore, it was observed that the linked fatty chains prevented PI to crystallize at low temperature $\left(-25^{\circ} \mathrm{C}\right)$. Finally, the addition of free fatty acids to the hybrid polymer enhanced the crystallization of the PI chain, more particularly when stearic acid and methyl linoleate were used simultaneously as additives. A 
similar investigation was performed with IR (with 97\% 1,4- cis and 3\% 1,2- units), identical observations could have been made.

\section{FIGURE FOR ToC ABSTRACT}

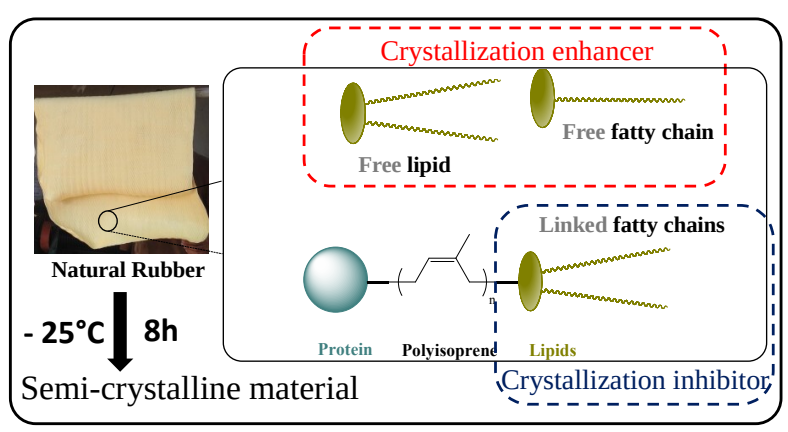

KEYWORDS: Natural Rubber, Elastomers, Functionalization of Polymers, Thermal Properties, Cold Crystallization. 


\section{Introduction}

Natural Rubber (NR) is one of the most important natural polymer as it is widely used in the industry for various applications (tires, gloves, etc....). ${ }^{[1]}$ It exhibits specific thermomechanical properties that cannot be obtained with synthetic polyisoprene (IR) such as strain induced crystallization (SIC), high green-strength, excellent crack resistance and fast cold crystallization (CCr). ${ }^{[2-5]}$ This later property corresponds to the crystallization of PI at low temperature (usually $-25^{\circ} \mathrm{C}$ ) without any external perturbations, contrarily to SIC which implies the deformation of the material. ${ }^{[6]}$ The origins of the superior capacities of NR are not yet fully understood despite the wide amount of studies carried out on this topic. Nevertheless, Tanaka et al. ${ }^{[7-10]}$ showed that it could arise from the structure of the polymer which was described to be composed of a polyisoprene (PI) chain functionalized at one chainend by a protein and at the other by a phospholipidic moiety (Figure 1). These chain-ends could self-assemble to form a dynamic network in the material thus explaining the superior mechanical properties of NR toward IR. ${ }^{[7]}$

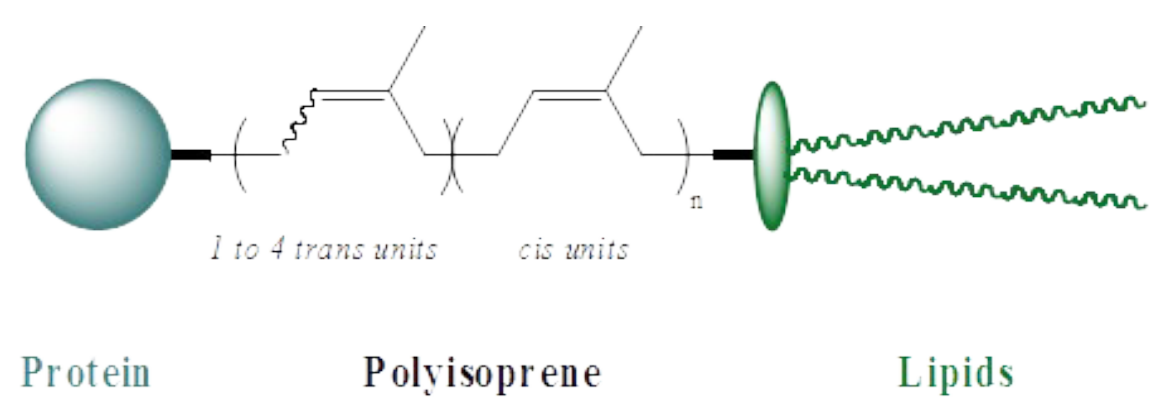

Figure 1: Structure of NR proposed by Tanaka

In 1946, Wood ${ }^{[11]}$ studied the crystallization of NR and showed that the fastest crystallization rate was obtained by keeping the material at $-25^{\circ} \mathrm{C}$ for several hours. Burfield established later that $75 \%$ of the final crystallinity could be reached after $3 \mathrm{~h}$ of isotherm and that total crystallization was observed after 16 h. ${ }^{[12]} \mathrm{CCr}$ was shown to be correlated to the suggested structure of NR (Figure 1) and more specifically to the lipidic chain-end. The influence of free 
fatty acid/esters present in NR was also investigated as well as their interaction with the PI chain. ${ }^{[13-20]}$ Kawahara et al. demonstrated that saturated fatty acids/esters (stearic acid being the main studied) enhanced the crystallization of NR and that unsaturated ones (methyl linoleate for example) had a plasticizing effect on the PI chain. ${ }^{[16]}$ Regardless the nature of the fatty acid, it was shown a synergetic effect between linked and free fatty chains as well as between stearic acid and methyl linoleate to promote the cold crystallization of the material. ${ }^{[19,21]}$ Similar studies were also performed on synthetic polyisoprenes. To this end, lipids were grafted onto IR by hydroboration using the pendant 3,4-units, leading to a model of $\mathrm{NR}^{\left[{ }^{[20]} \mathrm{A}\right.}$ fast crystallization was observed when the backbone was functionalized with 0.5 wt \% of stearic acid and mixed with 1 wt \% of methyl linoleate, but even if it was faster than the starting IR, it was still slower than NR. This difference could be related to the microstructure of NR, which is commonly accepted to be pure 1,4-cis contrarily to the IR used by Kawahara which contained about $2 \%$ of 1,2 and 3,4 units. $^{[22]}$

In this study, it was investigated the synthesis of new hybrid polymers formed from the functionalization of a pure 1,4-cis PI (molar mass of $\sim 10000 \mathrm{~g} / \mathrm{mol}$ ) with one or two fatty chains at one chain-end as a closer model of NR and their cold crystallization properties. Even if isoprene polymerization was already studied by many techniques (cationic, ${ }^{[23,24]}$ anionic, ${ }^{[25]}$ radical, ${ }^{[26-28]}$ metathesis, ${ }^{[29]}$ and coordination polymerization ${ }^{[30]}$, none of them allowed to reach a pure 1,4-cis microstructure with controlled chain-ends.

Oxidative degradation of NR by successive epoxidation and acidic degradation was preferred as it could lead to pure 1,4-cis PI with controlled molar mass and ketone and aldehyde reactive chain-ends. ${ }^{[31]}$ Reactive chain-ends could then be easily modified to graft lipidic moieties. The general synthetic strategy developed in this study is depicted on Figure 2. In this paper, the influence of the nature of fatty acids on the crystallization properties will be discussed as well as the influence of the addition of free lipids. Finally, modification of a 
synthetic polyisoprene will also be studied to try to mimic the crystallization properties of NR.

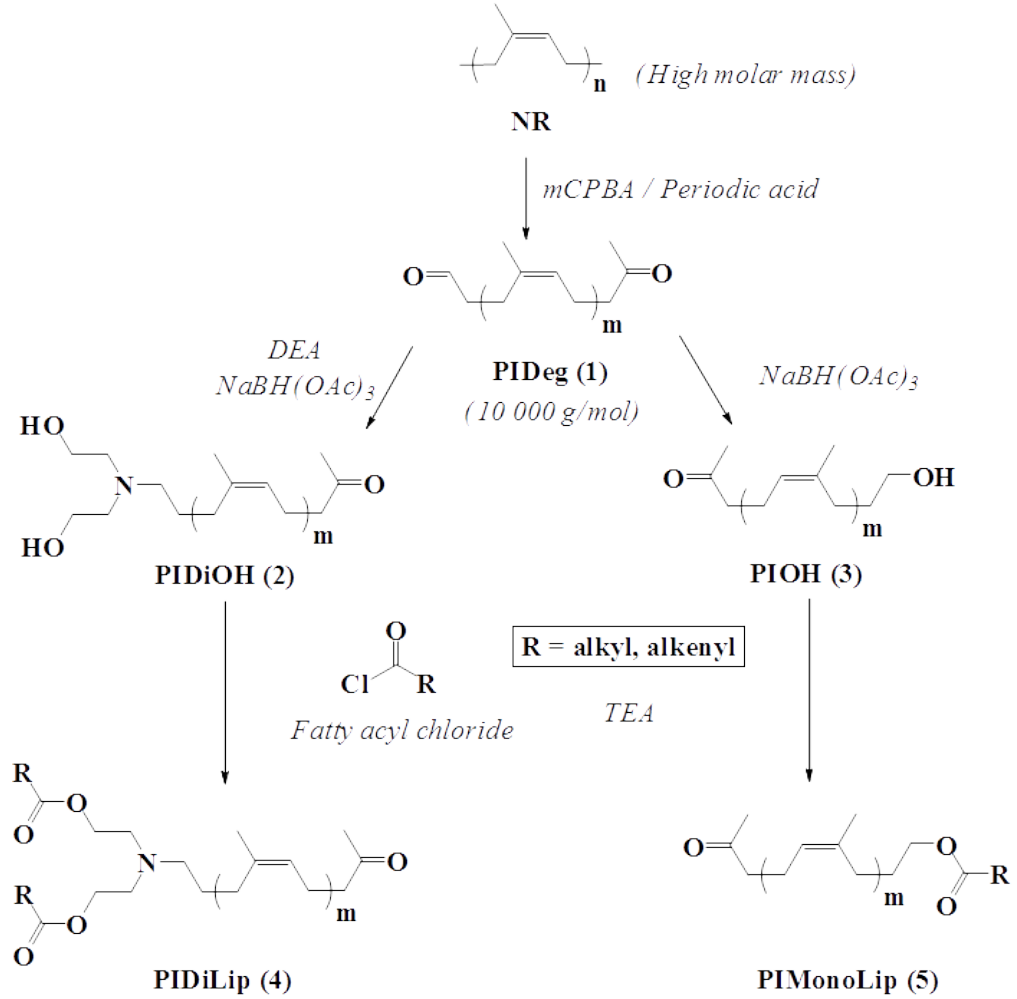

Figure 2: General synthetic route to obtain PIDi(or Mono)Lip

\section{Experimental Section}

\subsection{Materials}

Natural rubber (NR) RRIM600 was kindly provided by Katsetsart University in Thailand. Cis-1,4-polyisoprene (IR) (97\% cis-1,4, $\left.M_{n}=600 \mathrm{~kg} / \mathrm{mol}, Ð=2.8\right)$ was purchased from Scientific Polymer Products, Inc. 3-chloroperoxybenzoic acid (m-CPBA) (70-75\%, Acros), periodic acid $\left(\mathrm{H}_{5} \mathrm{IO}_{6}\right)(\geq 99 \%$, Aldrich), acetic acid (99\%, Aldrich), potassium hydroxide $(\mathrm{KOH})$ (85\%, Aldrich), sodium triacetoxyborohydride (NaBH(OAc) $)$ (97\%, Aldrich), diethanolamine (DEA) (99\%, Alfa Aesar), stearic acid (SA) (95\%, Aldrich), myristic acid (MA) (99\%, Aldrich), lignoceric acid (LA) (> 99\%, Aldrich), methyl linoleate (ML) (99\%, Aldrich), linoleoyl chloride (>99\%, Aldrich), 10-undecenoyl chloride (97\%, Aldrich), 
palmitoyl chloride (98\%, Aldrich), 3-aminopropyl-functionalized silica gel ( 1 mmol/g $\mathrm{NH}_{2}$

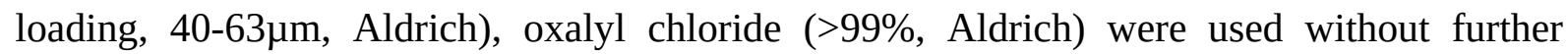
purification. Tetrahydrofuran (THF) and dichloromethane (DCM) were dried on alumina column. Triethylamine (TEA) was dried on $\mathrm{KOH}$ pellets and distilled prior to use. Methanol, diethyl ether, dimethylformamide (DMF) (reagent grade, Aldrich) as well as Celite ${ }^{\circledR}$ (R566, Aldrich) were used as received.

\subsection{Characterization}

Liquid-state 2D NMR, ${ }^{1} \mathrm{H}$ NMR and ${ }^{13} \mathrm{C}$ NMR spectra were recorded at $298 \mathrm{~K}$ on a Bruker Avance 400 spectrometer operating at $400 \mathrm{MHz}$ and $100 \mathrm{MHz}$ respectively in appropriate deuterated solvents. Polymer molar masses were determined by Size Exclusion Chromatography (SEC) using tetrahydrofuran as the eluent (THF with $250 \mathrm{ppm}$ of Butylated hydroxytoluene as inhibitor, Aldrich). Measurements were performed on a Waters pump equipped with Waters RI detector and Wyatt Light Scattering detector. The separation is achieved on three Tosoh TSK gel columns $(300 \times 7.8 \mathrm{~mm})$ G5000 HXL, G6000 HXL and a Multipore HXL with an exclusion limits from 500 to $40000000 \mathrm{~g} / \mathrm{mol}$, at a flow rate of 1 $\mathrm{mL} / \mathrm{min}$. The injected volume was $100 \mu \mathrm{L}$. Columns' temperature was $40{ }^{\circ} \mathrm{C} . \mathrm{M}_{\mathrm{n}}$ and $Ð$ values were calculated using $\mathrm{d} n / \mathrm{d} c$ (polyisoprene $)=0.130$. Data were processed with Astra software from Wyatt. Differential scanning calorimetry (DSC) measurements were performed using a DSC Q100 $\mathrm{LN}_{2}$ or a DSC Q100 RSC apparatus from TA Instruments depending on the experiment. With DSC Q100 $\mathrm{LN}_{2}$, the samples were first heated to $80^{\circ} \mathrm{C}$ during 20 minutes to suppress any trace of solvent then cooled to $-100^{\circ} \mathrm{C}$ and heated back to $120^{\circ} \mathrm{C}$ at a rate of $10^{\circ} \mathrm{C} \mathrm{min}^{-1}$. Consecutive cooling and heating run were also performed at $10^{\circ} \mathrm{C} \mathrm{min}^{-1}$. The analyses were carried out in a helium atmosphere with aluminum pans. DSC Q100 RSC device was used for isothermal analysis. The samples were heated at $80^{\circ} \mathrm{C}$ during 20 minutes 
prior to use to suppress any trace of solvent, then cooled to $-25^{\circ} \mathrm{C}$ during predetermined time and then heated to $120^{\circ} \mathrm{C}$ at a heating rate of $10^{\circ} \mathrm{C} \min ^{-1}$. Fourier Transformed Infra-RedAttenuated Total Reflection (FTIR-ATR) spectra were recorded between 4000 and $400 \mathrm{~cm}^{-1}$ on a Bruker VERTEX 70 instrument $\left(4 \mathrm{~cm}^{-1}\right.$ resolution, 32 scans, DLaTGS MIR) equipped with a Pike GladiATR plate (diamond crystal) for attenuated total reflectance (ATR) at room temperature.

\subsection{Synthesis}

\subsubsection{Synthesis of heterotelechelic keto-aldehyde PI (PIDeg) (1).}

NR (5 g) was dissolved overnight in $250 \mathrm{~mL}$ of THF under vigorous stirring. The viscous solution obtained was then cooled to $0^{\circ} \mathrm{C}$ and $50 \mathrm{~mL}$ of mCPBA $(0.14 \mathrm{~g}, 0.6 \mathrm{mmol})$ solution in THF were added dropwise to the NR solution. The reaction was then allowed to warm up to room temperature for $2 \mathrm{~h}$. Periodic acid (0.3 g, 2.2 eq compared to m-CPBA, $1.33 \mathrm{mmol}$ ) were dissolved in $50 \mathrm{~mL}$ of THF and added dropwise to the epoxidized NR solution. After $2 \mathrm{~h}$ of stirring at room temperature, the reaction mixture was filtered affording a yellow solution which was then concentrated in vacuum and precipitated into a large excess of cold methanol containing $2 \mathrm{~mL}$ of alkaline water. The polymer was then dissolved in diethyl ether $(\sim 100$ $\mathrm{mL}$ ) and the obtained cloudy solution was filtered on Celite ${ }^{\circledR}$. The final product was obtained by evaporation of the $\mathrm{Et}_{2} \mathrm{O}$ and drying overnight at $40^{\circ} \mathrm{C}$ under dynamic vacuum affording a yellowish and transparent viscous liquid. Yield: $80 \%, \mathrm{M}_{\mathrm{n}}=9620 \mathrm{~g} / \mathrm{mol}, \mathrm{Ð}=1.6$ (Figure

S1). ${ }^{1} \mathrm{H}$ NMR ( $\mathrm{CDCl}_{3}$, Figure S2) $\delta(\mathrm{ppm}): 9.77$ (t, $\left.1 \mathrm{H}_{\text {chain-end, }} \mathrm{CH}_{2} \mathrm{CHO}\right), 5.13$ (t, $1 \mathrm{H}$ $\left.\mathrm{CH}=\mathrm{CCH}_{3}\right), 2.49$ (t, 2H, CH $\left.\mathrm{H}_{2} \mathrm{CHO}\right), 2.44$ (t, 2H, $\left.\mathrm{CH}_{2} \mathrm{COCH}_{3}\right), 2.35$ (t, 2H, $\mathrm{CH}_{2} \mathrm{CH}_{2} \mathrm{CHO}$ ), 2.13 (s, 3H, $\mathrm{CH}_{3} \mathrm{COCH}_{2}$ ), 2.05 (s, 4H, $\mathrm{CH}_{2} \mathrm{CH} / \mathrm{CH}_{2} \mathrm{CCH}_{3}$ ), 1.68 (s, $\mathrm{CH}_{3} \mathrm{CCH}$ ). FTIR (Figure 
S3): $v_{\mathrm{H}-\mathrm{C}=\mathrm{C}}: 3035 \mathrm{~cm}^{-1} ; v_{\mathrm{CH}}, \mathrm{CH}_{3}: 2900-2730 \mathrm{~cm}^{-1} ; v_{\mathrm{C}}=\mathrm{O}: 1722 \mathrm{~cm}^{-1} ; \delta_{\mathrm{C}}=\mathrm{C}: 1664$ $\mathrm{cm}^{-1} ; \mathrm{n}_{\mathrm{CH} 2} \cdot \mathrm{CH} 3$ cis-1,4-: 1446, $1375 \mathrm{~cm}^{-1} ; \delta_{\mathrm{C}=\mathrm{C}-\mathrm{H}}: 833 \mathrm{~cm}^{-1}$

\subsubsection{Synthesis of heterotelechelic keto-diol PI (PIDiOH) (2).}

PIDeg (3.7 g, $0.37 \mathrm{mmol}$ of aldehyde groups) was dissolved in $10 \mathrm{~mL}$ of dry THF. Diethanolamine (0.19 g, $4.5 \mathrm{eq}, 1.66 \mathrm{mmol})$ was added and the reaction was stirred at $40^{\circ} \mathrm{C}$ for 2 h. Finally, sodium triacetoxyborohydride ( $0.36 \mathrm{~g}, 4.2 \mathrm{eq}, 1.55 \mathrm{mmol})$ was added to the reaction mixture followed by acetic acid (30 $\mu \mathrm{L}, 1.3 \mathrm{eq}, 0.48 \mathrm{mmol})$. The heterogeneous medium was stirred at $40^{\circ} \mathrm{C}$ overnight. The reaction mixture was then directly precipitated into a large excess of cold methanol under vigorous stirring. The polymer was further dissolved in DCM and precipitated again in cold methanol, dissolved in $\mathrm{Et}_{2} \mathrm{O}$, filtered on Celite ${ }^{\circledR}$ and dried under vacuum at $40{ }^{\circ} \mathrm{C}$ overnight affording a colorless viscous liquid. Yield:

85 \%. ${ }^{1} \mathrm{H}$ NMR $\left(\mathrm{CD}_{2} \mathrm{Cl}_{2}\right.$, Figure S5) $\delta(\mathrm{ppm}): 5.14$ (s, $\left.1 \mathrm{H}, \mathrm{CH}=\mathrm{CCH}_{3}\right), 3.57$ (t, 4H, $\left.\left(\mathrm{CH}_{2}\right)_{2} \mathrm{OH}\right), 2.64\left(\mathrm{t}, 4 \mathrm{H}, \mathrm{N}\left(\mathrm{CH}_{2}\right)_{2}\right), 2.52\left(\mathrm{t}, 2 \mathrm{H}, \mathrm{CH}_{2} \mathrm{~N}\right), 2.42$ (t, 2H, $\left.\mathrm{CH}_{2} \mathrm{COCH}_{3}\right), 2.05(\mathrm{~s}, 4 \mathrm{H}$, $\left.\mathrm{CH}_{2} \mathrm{CH} / \mathrm{CH}_{2} \mathrm{CCH}_{3}\right), 1.67$ (s, 3H, $\left.\mathrm{CH}_{3} \mathrm{CCH}\right)$

\subsubsection{Synthesis of heterotelechelic keto-hydroxyl PI (PIOH) (3).}

PIDeg (2 g, $0.2 \mathrm{mmol}$ of aldehyde groups) was dissolved in $5 \mathrm{~mL}$ of dry THF. Triacetoxyborohydride (0.19 g, 4 eq, $0.8 \mathrm{mmol})$ as well as acetic acid (12 $\mu \mathrm{L}, 1 \mathrm{eq}, 0.2 \mathrm{mmol})$ were then added. The reaction mixture was stirred at $40{ }^{\circ} \mathrm{C}$ overnight and the final product was obtained after two successive precipitations into a large excess of cold methanol, dissolution in $\mathrm{Et}_{2} \mathrm{O}$, filtration through Celite ${ }^{\circledR}$ and drying overnight at $40^{\circ} \mathrm{C}$ under dynamic vacuum. The $\mathrm{PIOH}$ is a viscous and colorless liquid. Yield: $~ 90 \% .{ }^{1} \mathrm{H}$ NMR $\left(\mathrm{CDCl}_{3}\right.$, Figure S12) $\delta(\mathrm{ppm}): 5.12\left(\mathrm{t}, 1 \mathrm{H}, \mathrm{CH}=\mathrm{CCH}_{3}\right), 3.62\left(\mathrm{t}, 2 \mathrm{H}, \mathrm{CH}_{2} \mathrm{OH}\right), 2.42\left(\mathrm{t}, 2 \mathrm{H}, \mathrm{CH}_{2} \mathrm{COCH}_{3}\right), 2.05$ (s, $\left.4 \mathrm{H}, \mathrm{CH}_{2} \mathrm{CH} / \mathrm{CH}_{2} \mathrm{CCH}_{3}\right), 1.67$ (s, 3H, $\left.\mathrm{CH}_{3} \mathrm{CCH}\right)$ 


\subsubsection{Synthesis of fatty acyl chlorides $\left(\mathbf{C}_{\mathbf{1 4 : 0}} \mathbf{C h l o} / \mathbf{C}_{\mathbf{1 8 : 0}} \mathbf{C h l o} / \mathbf{C}_{24: 0} \mathbf{C h l o}\right)$.}

A solution of the desired fatty acid was prepared in dry DCM ([fatty acid] $=0.5 \mathrm{M}$ ). Oxalyl chloride ( 3 eq) was then added to the mixture under vigorous stirring followed by 3 drops of DMF. A vigorous bubbling was observed. The reaction conversion was followed by connecting the reaction flask to a bubbler containing a $\mathrm{KOH}$ solution. When bubbling was no more visible, the reaction mixture was evaporated under vacuum to remove the solvent and the excess of oxalyl chloride. The final product was then dried overnight at $40^{\circ} \mathrm{C}$ under dynamic vacuum affording a yellowish liquid for $\mathrm{C}_{18: 0}$ Chlo and $\mathrm{C}_{14: 0} \mathrm{Chlo}$ and a white powder for $\mathrm{C}_{24: 0}$ Chlo. Yield: > $90 \%$.

C 14:0 $_{\text {Chlo: }}{ }^{1} \mathrm{H}$ NMR $\left(\mathrm{CDCl}_{3}\right.$, Figure S7) $\delta(\mathrm{ppm}): 2.87\left(\mathrm{t}, 2 \mathrm{H}, \mathrm{CH}_{2} \mathrm{CCl}\right), 1.70(\mathrm{~m}, 2 \mathrm{H}$, $\mathrm{CH}_{2} \mathrm{CH}_{2} \mathrm{Cl}$ ), $1.25\left(\mathrm{~s}, 20 \mathrm{H},\left(\mathrm{CH}_{2}\right)_{10}\right), 0.88\left(\mathrm{t}, 3 \mathrm{H}, \mathrm{CH}_{3} \mathrm{CH}_{2}\right) ;{ }^{13} \mathrm{C}$ NMR $\left(\mathrm{CDCl}_{3}\right.$, Figure S8) $\delta$ (ppm): 174.21 (1C, COCl), $47.28\left(1 \mathrm{C}, \mathrm{COCH}_{2}\right), 31.93\left(1 \mathrm{C}, \mathrm{COCH}_{2} \mathrm{CH}_{2}\right),[29.65,29.64$,

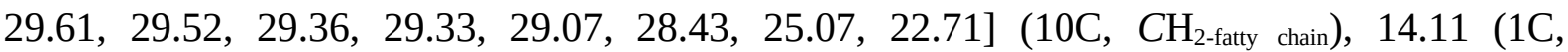
$\left.\mathrm{CH}_{2} \mathrm{CH}_{3}\right) . \mathbf{C}_{\mathbf{1 8 : 0}}$ Chlo: ${ }^{1} \mathrm{H}$ NMR, $\left(\mathrm{CDCl}_{3}\right.$, Figure S7) $\delta(\mathrm{ppm}): 2.87$ (t, 2H, $\left.\mathrm{CH}_{2} \mathrm{CCl}\right), 1.70$ (m, $2 \mathrm{H}, \mathrm{CH}_{2} \mathrm{CH}_{2} \mathrm{Cl}$ ), 1.25 (s, 28H, $\mathrm{CH}_{2}$, fatty chain), 0.88 (t, 3H, $\left.\mathrm{CH}_{3} \mathrm{CH}_{2}\right) ;{ }^{13} \mathrm{C} \mathrm{NMR}\left(\mathrm{CDCl}_{3}\right.$, Figure S8) $\delta$ (ppm): 174.21 (1C, $\mathrm{COCl}), 47.28\left(1 \mathrm{C}, \mathrm{COCH}_{2}\right)$, 31.93 (1C, $\left.\mathrm{COCH}_{2} \mathrm{CH}_{2}\right)$, [29.81, 29.75,

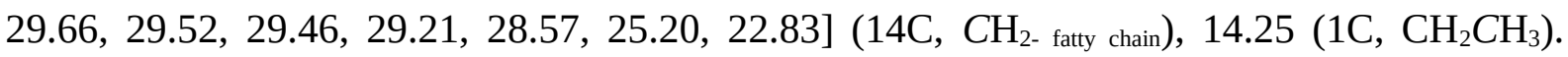
$\mathbf{C}_{\text {24:0 }}$ Chlo: ${ }^{1} \mathrm{H}$ NMR, $\left(\mathrm{CDCl}_{3}\right.$, Figure S7) $\delta(\mathrm{ppm}): 2.87\left(\mathrm{t}, 2 \mathrm{H}, \mathrm{CH}_{2} \mathrm{CCl}\right), 1.70(\mathrm{~m}, 2 \mathrm{H}$, $\mathrm{CH}_{2} \mathrm{CH}_{2} \mathrm{Cl}$ ), 1.25 (s, 40H, $\mathrm{CH}_{2}$, fatty chain), 0.88 (t, 3H, $\left.\mathrm{CH}_{3} \mathrm{CH}_{2}\right) ;{ }^{13} \mathrm{C} \mathrm{NMR}\left(\mathrm{CDCl}_{3}\right.$, Figure S8) $\delta$ (ppm): $174.21(1 \mathrm{C}, \mathrm{COCl}), 47.28\left(1 \mathrm{C}, \mathrm{COCH}_{2}\right), 31.93\left(1 \mathrm{C}, \mathrm{COCH}_{2} \mathrm{CH}_{2}\right),[29.86,29.76$,

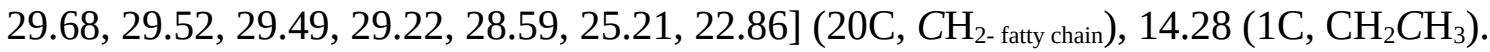




\subsubsection{Synthesis of heterotelechelic keto-dilipid PI (PIDiLip) (4).}

PIDiOH (2 g, 0.2 mmol of hydroxyl groups) was dissolved in $7 \mathrm{~mL}$ of dry THF. TEA (180 $\mu \mathrm{L}, 6$ eq, $1.2 \mathrm{mmol}$ ) was then added followed by the desired acyl chloride (3 eq, $0.6 \mathrm{mmol}$ ). After $1 \mathrm{~h}$ of reaction, 3-aminopropyl-functionalized silica particles were added $\left(\sim 1 \mathrm{NH}_{2}\right.$ eq toward acyl chloride) and the mixture was stirred for $2 \mathrm{~h}$. The reaction medium was then precipitated in a large excess of cold methanol, dissolved in $\mathrm{Et}_{2} \mathrm{O}$, filtered through Celite ${ }^{\circledR}$ and dried first on rotary evaporator and then overnight at $40^{\circ} \mathrm{C}$ under vacuum. The final compound was a colorless viscous liquid except for PIDiC $_{24: 0}$ which was a colorless paste. Yield: 80 \%. ${ }^{1} \mathrm{H}$ NMR $\left(\mathrm{CD}_{2} \mathrm{Cl}_{2}\right.$, Figure S9) $\delta$ (ppm): 5.12 (s, $\left.1 \mathrm{H}, \mathrm{CH}=\mathrm{CCH}_{3}\right), 4.09(\mathrm{t}, 4 \mathrm{H}$, $\left.\left(\mathrm{CH}_{2}\right)_{2} \mathrm{OCO}\right), 2.74\left(\mathrm{t}, 4 \mathrm{H}, \mathrm{N}\left(\mathrm{CH}_{2}\right)_{2}\right), 2.51\left(\mathrm{t}, 2 \mathrm{H}, \mathrm{CH}_{2} \mathrm{~N}\right), 2.43\left(\mathrm{t}, 2 \mathrm{H}, \mathrm{CH}_{2} \mathrm{CCH}_{3}\right), 2.26(\mathrm{t}, 4 \mathrm{H}$, $\left.\mathrm{OCOCH}_{2}\right) 2.05$ (s, 4H, $\mathrm{CH}_{2} \mathrm{CH} / \mathrm{CH}_{2} \mathrm{CCH}_{3}$ ), 1.67 (s, 3H, $\mathrm{CH}_{3} \mathrm{CCH}$ ), 1.26 (s, $\mathrm{CH}_{2}$, fatty chain), 0.88 (t, 6H, $\mathrm{CH}_{2} \mathrm{CH}_{3}$ ).

\subsubsection{Synthesis of heterotelechelic keto-monolipid PI (PImonoLip) (5).}

PIOH (1 g, 0.1 mmol of hydroxyl groups) was dissolved in $4 \mathrm{~mL}$ of dry THF. TEA (60 $\mu \mathrm{L}, 4$ eq, $0.4 \mathrm{mmol}$ ) was added followed by the desired acyl chloride (2 eq, $0.2 \mathrm{mmol}$ ). After $1 \mathrm{~h}$ of reaction, 3-aminopropyl-functionalized silica particles were added ( $\sim \mathrm{NH}_{2}$ eq toward acyl chloride) and the obtained mixture was stirred for $2 \mathrm{~h}$. The final polymer was obtained after two successive precipitations into a large excess of cold methanol, dissolving in $\mathrm{Et}_{2} \mathrm{O}$, filtration through Celite ${ }^{\circledR}$ and overnight drying at $40^{\circ} \mathrm{C}$ under dynamic vacuum. Yield: $80 \%$. ${ }^{1} \mathrm{H}$ NMR ( $\mathrm{CDCl}_{3}$, Figure S13) $\delta(\mathrm{ppm}): 5.12$ (s, $\left.1 \mathrm{H}, \mathrm{CH}=\mathrm{CCH}_{3}\right), 4.03\left(\mathrm{t}, 2 \mathrm{H}, \mathrm{CH}_{2} \mathrm{OCO}\right), 2.43$ (t, $2 \mathrm{H}, \mathrm{CH}_{2} \mathrm{CCH}_{3}$ ), 2.26 (t, 2H, $\left.\mathrm{OCOCH}_{2}\right) 2.05$ (s, 4H, $\mathrm{CH}_{2} \mathrm{CH} / \mathrm{CH}_{2} \mathrm{CCH}_{3}$ ), 1.67 (s, 3H,

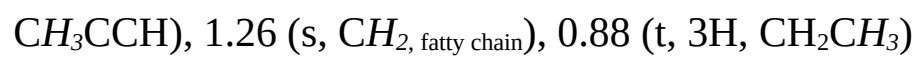

\section{Results and Discussion}




\subsection{Polymer modification.}

\subsubsection{Synthesis of PIDeg (1)}

The epoxidation and the acidic degradation (Figure 2) were performed successively without intermediate purification. During the precipitation step in methanol, the use of alkaline water was compulsory to prevent acetal formation at the aldehyde chain-end. In this study, $10000 \mathrm{~g} /$ mol PIDeg was targeted.

The targeted molar mass can be adjusted by using the following formula:

$$
\begin{aligned}
& \dot{M}_{n}=\frac{100 * 68}{T_{x}}+100 \\
& T_{x}=\frac{[\text { epoxidized units }]}{[\text { monomer units }]} * 100 \% \dot{M}_{n}: \text { Targeted molar mass }(\mathrm{g} / \mathrm{mol})
\end{aligned}
$$

The progress of the degradation reaction was monitored by SEC, ${ }^{1} \mathrm{H}$ NMR, 2D NMR and FTIR-ATR analyses (Figures S1 to S4). By SEC, it was observed a decrease of the molar mass from $500000 \mathrm{~g} / \mathrm{mol}$ (NR) to $10000 \mathrm{~g} / \mathrm{mol}$ (PIDeg) as well as a decrease of the molar mass distribution from 2.6 (NR) to 1.6 (PIDeg). The formation of carbonyl chain-ends was confirmed by ${ }^{1} \mathrm{H}$ NMR with the appearance of a triplet at $9.77 \mathrm{ppm}$ characteristic of the aldehyde proton as well as the appearance of 3 triplets at 2.49, 2.44 and 2.35 ppm corresponding to " $\mathrm{CH}_{2}$ " groups in $\alpha$ and $\beta$ position of the aldehyde and in $\alpha$ position of ketone chain-end respectively. Moreover, the appearance of a band at $1722 \mathrm{~cm}^{-1}$ in FTIR-ATR also confirmed the generation of carbonyl functions.

\subsubsection{Synthesis of PIDiLip (4)}

For the synthesis of PIDiLip (4), the reductive amination of the aldehyde chain-end of (1) with diethanolamine and $\mathrm{NaBH}(\mathrm{OAc})_{3}$ was first performed to yield PIDiOH (2). Compared to the procedure described in the literature ${ }^{[32]}$, the solvent was changed, THF instead of 
DMSO/dichloroethane mixture, giving a higher reaction rate. ${ }^{1} \mathrm{H}$ NMR analysis (Figure S5) showed a quantitative conversion with the total disappearance of the signals at 9.77, 2.49 and 2.35 ppm corresponding to the aldehydic proton and both " $\mathrm{CH}_{2}$ " groups in $\alpha$ and $\beta$ position of the aldehyde chain-end respectively. Furthermore, the appearance of signals at 3.57, 2.64 and $2.52 \mathrm{ppm}$ corresponding to both " $\mathrm{CH}_{2}$ ” groups in $\alpha$ and $\beta$ position of the hydroxyl function and to the " $\mathrm{CH}_{2}$ " group in $\alpha$ position of the nitrogen atom respectively also confirmed the good control of the reaction. Finally, the selectivity was confirmed by the presence of the signal at $2.43 \mathrm{ppm}$ corresponding to the " $\mathrm{CH}_{2}$ " group in $\alpha$ position of the ketone chain-end. It was confirmed by 2D NMR analysis (Figure S6). The following step was to add two fatty chains at the $\mathrm{DiOH}$ chain-end through acylation reactions affording (4). The corresponding fatty acyl chlorides were first synthesized through the reaction of fatty acids with oxalyl chloride in dichloromethane with excellent yields (Figures S7 and S8). As confirmed by the total shift of the signal at $2.35 \mathrm{ppm}$ in ${ }^{1} \mathrm{H}$ NMR corresponding to the " $\mathrm{CH}_{2}$ " group in $\alpha$ position of the carboxylic acid carbonyl to a signal at $2.87 \mathrm{ppm}$ after the chlorination. Moreover, on ${ }^{13} \mathrm{C}$ NMR spectrum, the shift of the signal at $182 \mathrm{ppm}$ corresponding to the carbon of the carboxylic acid carbonyl to a signal at $174.21 \mathrm{ppm}$ after chlorination also confirms the full conversion. These acyl chlorides were then reacted with (2) in dry THF in the presence of triethylamine. Again, ${ }^{1} \mathrm{H}$ NMR analysis (Figures S9 and S10) confirmed full conversion with the total shift of the signal at $3.57 \mathrm{ppm}$ corresponding to the " $\mathrm{CH}_{2}$ " group in $\alpha$ position of the hydroxyl chain-end to a new signal at $4.09 \mathrm{ppm}$ corresponding to the " $\mathrm{CH}_{2}$ " group in $\alpha$ position of the formed ester. 2D NMR also confirmed the full conversion (Figure S11). The use of the silica beads functionalized by amino-propyl groups is important as it prevents contamination of the product by di-ketene (side product) formed during the reaction $^{[33]}$ and removes the excess of unreacted acyl chloride. No change on the SEC 
chromatogram was observed, attesting that no cross-linking occurred during the overall pathway.

\subsubsection{Synthesis of PIMonoLip (5)}

For the synthesis of PIMonoLip (5), aldehyde chain-end of PIDeg (1) was first selectively reduced with $\mathrm{NaBH}(\mathrm{OAc})_{3}$, a reducing agent known for its selectivity toward aldehydes against ketone, ${ }^{[34]}$ to yield $\mathrm{PIOH}$ (3). ${ }^{1} \mathrm{H}$ NMR analysis (Figure S12) confirmed the quantitative conversion with the disappearance of the signals at 9.77, 2.49 and 2.35 from (1) corresponding to the aldehydic proton and both " $\mathrm{CH}_{2}$ " groups in $\alpha$ and $\beta$ position of the aldehyde chain-end respectively. A new signal appeared at $3.62 \mathrm{ppm}$ corresponding to the signal of the " $\mathrm{CH}_{2}$ " group in $\alpha$ position of the newly formed hydroxyl function. The last step was the addition of one fatty chain via an esterification reaction similarly to the synthesis of (4). Again, the reaction was carried out in dry THF using fatty acyl chlorides and triethylamine as a proton trap. The ${ }^{1} \mathrm{H}$ NMR analysis (Figure S13) showed a quantitative conversion with the total shift of the signal at $3.62 \mathrm{ppm}$ corresponding to the " $\mathrm{CH}_{2}$ " group in $\alpha$ position of the hydroxyl chain-end to a signal at $4.03 \mathrm{ppm}$ corresponding to the same group in $\alpha$ position of the new ester function. No change in the SEC chromatogram was observed attesting that no side reaction occurred.

\subsection{Thermal analysis of the hybrid polymers synthesized}

First, regular DSC analyses of the PIDiLip were performed. Figure 3 shows the DSC thermogram obtained for $\mathrm{PIDiC}_{18: 0}$. It can be observed a $\mathrm{T}_{\mathrm{g}}$ at $-63^{\circ} \mathrm{C}$ as well as a crystallization (and a melting) at low temperature for the hybrid polymer, whereas for NR, PIDeg and PIDiOH (Figures S14 to S16), only a $\mathrm{T}_{\mathrm{g}}$ at $-63^{\circ} \mathrm{C}$ was observed. This could not be due to PI crystallization which was reported to be slow, occurring only while maintaining the rubber at 
low temperature (usually $-25^{\circ} \mathrm{C}$ ) for a long time. It can then be assumed that the lipids linked at the chain-ends could crystallize. Furthermore, it was possible to tune the crystallization and melting temperature of the chain-ends by varying the nature of the fatty acid as indicated on Table 1. Indeed, $\mathrm{T}_{\mathrm{m}}$ and $\mathrm{T}_{\mathrm{c}}$ increased with the fatty acid chain length (Figures $\mathrm{S} 17$ to $\mathrm{S} 22$ ). For instance, $\mathrm{T}_{\mathrm{m}}$ increased from -25 to $22^{\circ} \mathrm{C}$ for $\mathrm{C}_{16: 0}$ and $\mathrm{C}_{24: 0}$ respectively.

Nevertheless, for unsaturated fatty acids $\left(\mathrm{C}_{11: 1}\right.$ and $\left.\mathrm{C}_{18: 2}\right)$ and smaller saturated fatty acid $\left(\mathrm{C}_{14: 0}\right)$, no crystallization occurred. For PIDiC $_{24: 0}$, as the melting temperature is close to room temperature, the material became more viscous due to partial crystallization. In the case of

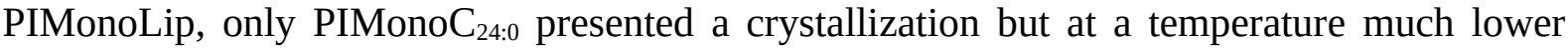
than $\mathrm{PIDiC}_{24: 0}\left(-35^{\circ} \mathrm{C}\right.$ instead of $\left.17^{\circ} \mathrm{C}\right)$. This suggests that the number of chains grafted to the polymer backbone is also an important parameter for the chain-end crystallization.

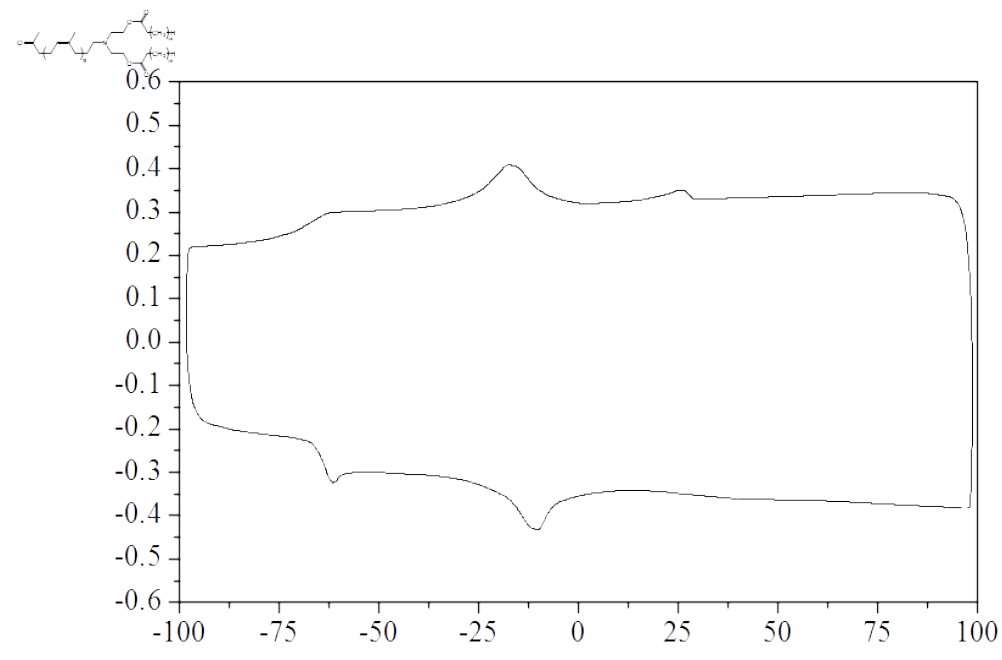

Figure 3: DSC thermogram of PIDiC $18: 0$

Table 1. Crystallization and melting temperatures of various PiDiLip observed by DSC

\begin{tabular}{ccc}
\hline Grafted fatty acid & $\mathrm{T}_{\mathrm{m}}{ }^{\mathrm{a})}$ & $\mathrm{T}_{\mathrm{c}}{ }^{\mathrm{b})}$ \\
& $\left({ }^{\circ} \mathrm{C}\right)$ & $\left({ }^{\circ} \mathrm{C}\right)$ \\
\hline Undecenoic acid $(\mathrm{C} 11: 1)$ & $-^{\mathrm{c})}$ & $-^{\mathrm{c}}$
\end{tabular}




$\begin{array}{ccc}\text { Linoleic acid (C18:2) } & -{ }^{c)} & \text {-c) } \\ \text { Myristic acid (C14:0) } & -c) & -c) \\ \text { Palmitic acid (C16:0) } & -25 & -37 \\ \text { Stearic acid (C18:0) } & -11 & -18 \\ \text { Nonadecanoic acid (C19:0) } & -5 & -13 \\ { }^{\text {a) }} \text { Melting temperature observed by DSC; }{ }^{\text {b) }} \text { Crystallization temperature observed by DSC; }{ }^{c} \\ \text { No crystallization or melting observed by DSC }\end{array}$

In a second step, as PIDiLip were tought to be simple models of NR, it was decided to study their cold crystallization behavior. DSC analysis was used to study the crystallization of the starting NR after 2 and $8 \mathrm{~h}$ of isotherm at $-25^{\circ} \mathrm{C}$ (Erreur : source de la référence non trouvée).

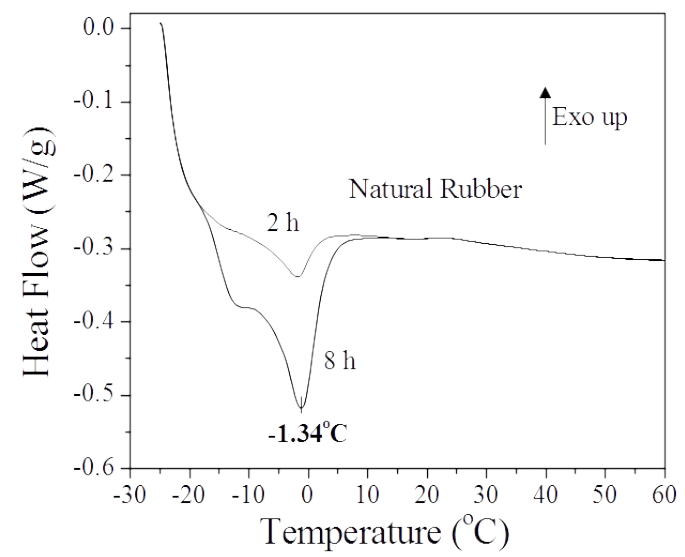

Figure 4: DSC thermograms of NR obtained after $2 \mathrm{~h}$ and $8 \mathrm{~h}$ at $-25^{\circ} \mathrm{C}$

It can be seen, as reported in the literature, that the crystallization process is quite long as only a small melting endotherm can be observed after $2 \mathrm{~h}$ at $-25{ }^{\circ} \mathrm{C}$. Interestingly, exothermal crystallization peak can be observed during the isotherm as a function of time (Figure 5). It was defined in the literature different characteristic times: $t_{i}$ (induction time, corresponding to the starting time of isothermal analysis), $\mathrm{t}_{\mathrm{m}}$ (time of maximum crystallization, i.e the time at which the maximum of the plot is observed) and $t_{\mathrm{e}}$ (extrapolated time, i.e the time at which the crystallization is effectively starting). A fourth value was added, $\mathrm{t}_{\mathrm{f}}$, corresponding to the 
time at which the crystallization is finished (see Figure 5 line b). Similar analyses were then achieved for PIDeg and PIDiOH (Figure 5).

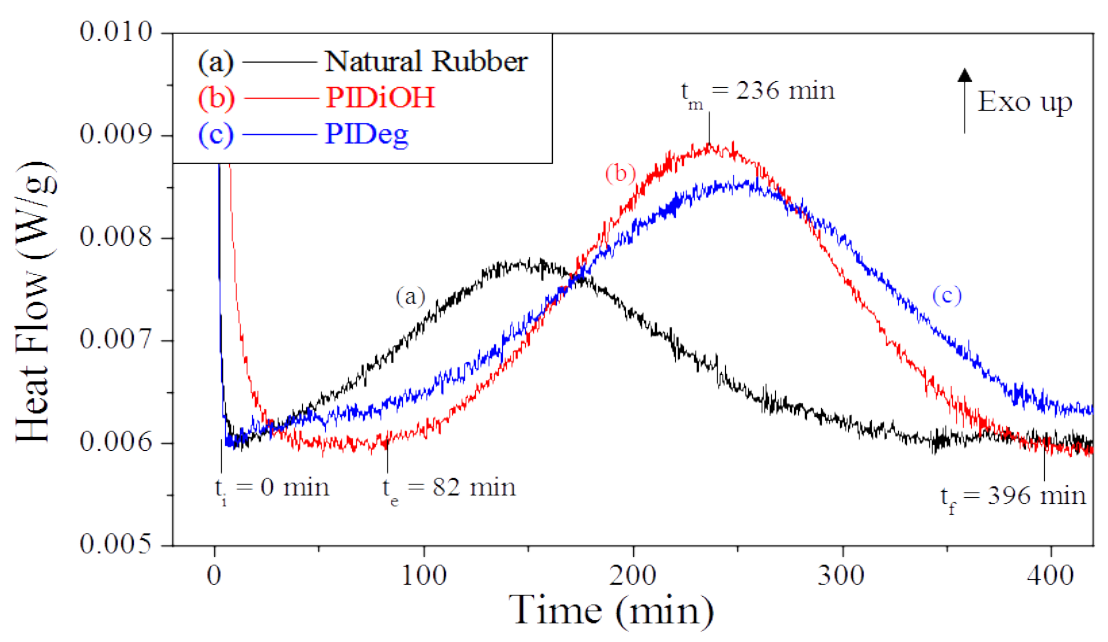

Figure 5: DSC thermograms obtained for $8 \mathrm{~h}$ isothermal crystallization at $-25^{\circ} \mathrm{C}$ of NR, PIDiOH and PIDeg

All the characteristic times are summarized in as well as the melting temperatures obtained for each sample by performing DSC heating cycle following isothermal crystallization. For PIDiOH and PIDeg, the crystallization started with a delay ( $\mathrm{t}_{\mathrm{e}}: 93$ and $82 \mathrm{~min}$ for PIDeg and PIDiOH respectively) but maximum of heat flow was achieved after similar crystallization time for all three polymers $\left(\mathrm{t}_{\mathrm{m}}-\mathrm{t}_{\mathrm{e}} \approx 150\right)$, as well as crystallization finished in $\sim 320$ min $\left(\mathrm{t}_{\mathrm{f}}-\mathrm{t}_{\mathrm{e}}\right)$ in all three cases. In the literature, such a delay was only observed for acetone extracted NR (AE-NR) (removal of the free fatty chains by acetone extraction) or trans-esterified NR (TENR) (removal of both linked and free fatty chains). In our case, it could thus mean that controlled degradation removed free and/or linked fatty chains from the initial NR but that the reductive amination had no effect. Finally, an increase of the overall crystallinity of the PIDeg and PIDiOH was observed compared to the initial NR (higher enthalpy), which is in agreement with the literature ${ }^{[21]}$, as Kawahara reported a delayed crystallization of TE-NR compared to NR but a higher final crystallinity. 
Table 2. Characteristic values of CCr of NR, PIDeg and PIDiOH obtained for $8 \mathrm{~h}$ isothermal crystallization at -

$25^{\circ} \mathrm{C}$

\begin{tabular}{ccccccc}
\hline Sample & $\mathrm{t}_{\mathrm{i}}^{\mathrm{a})}$ & $\mathrm{t}_{\mathrm{e}}^{\mathrm{a})}$ & $\mathrm{t}_{\mathrm{m}}{ }^{\mathrm{a})}$ & $\mathrm{t}_{\mathrm{f}}^{\mathrm{a})}$ & $\Delta \mathrm{H}_{\mathrm{m}}{ }^{\mathrm{b})}$ & $\mathrm{T}_{\mathrm{m}}{ }^{\mathrm{c})}$ \\
& $(\mathrm{min})$ & $(\mathrm{min})$ & $(\mathrm{min})$ & $(\mathrm{min})$ & $(\mathrm{J} / \mathrm{g})$ & $\left({ }^{\circ} \mathrm{C}\right)$ \\
\hline NR (RRIM 600) & 0 & 0 & 146 & 338 & 14 & -1 \\
PIDeg & 0 & 93 & 249 & 408 & 23 & -1 \\
PIDiOH & 0 & 82 & 236 & 396 & 21 & 0
\end{tabular}

a) Characteristic times obtained from the DSC thermograms; ${ }^{b)}$ Melting enthalpy calculated from the area of the melting endotherm on the DSC thermograms. ${ }^{c)}$ Melting temperatures obtained from the DSC thermograms

The cold crystallization of PIDiC $_{18: 0}$ was then investigated and compared to the one of PIDiOH (Figure 6). Endotherm peaks were visible in both cases. Nevertheless, in the case of PIDiOH, the observed endotherm corresponded to the melting of the crystallized PI chains, whereas for PIDIC $_{18: 0}$, the endotherm was due to the melting of the chain-ends as the melting temperature is lower than the one of PI chains and corresponds to the $T_{m}$ of the chain-ends during regular DSC cycle (Figure 3, Table 2). The grafted fatty chains at one chain-end seemed then to prevent (or at least significantly decrease) the CCr of the polymeric chains. This observation is in good agreement with the literature as AE-NR (only containing linked lipids) presented a huge decrease in the crystallization rate.

The effect of the number of linked fatty chains was also investigated. In the case of PIMonoLip, no PI crystallization was observed (Figure S23). Tanaka suggested that grafting fatty chains onto PI decreases the "purity” of the sample thus rendering the crystallization less favorable. ${ }^{[14]}$ In our case, the absence of crystallization of PI even after $8 \mathrm{~h}$ of isotherm can be related to the mass fraction of lipids which acted as a huge quantity of "impurities" in the case of $\mathrm{PIDiC}_{18: 0}(5.7 \mathrm{wt} \%)$. 


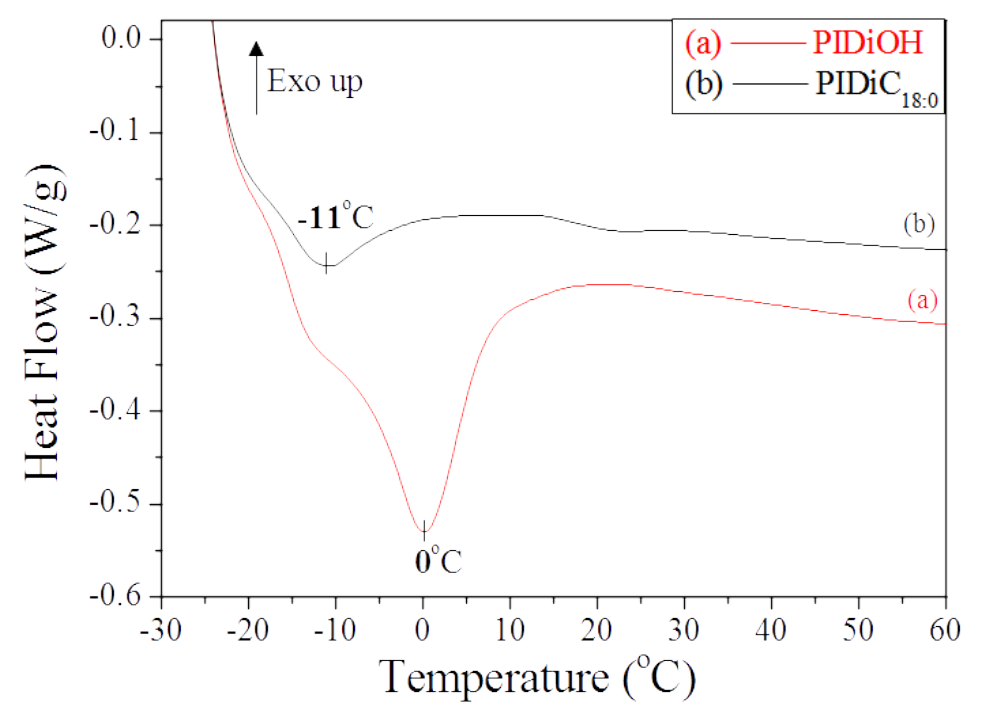

Figure 6: DSC thermograms of a PIDiC $18: 0$ and PIDiOH after $8 \mathrm{~h}$ of isothermal crystallization at $-25^{\circ} \mathrm{C}$

In a last step, free lipids were added to try to recover a cold crystallization for the hybrid material. Indeed, methyl linoleate (ML) and stearic acid (SA), which represent the major part of the lipids in the Hevea $\mathrm{NR}^{[35]}$, were reported to have a nucleating effect for $\mathrm{SA}$ and a plasticizing effect for ML on the CCr of NR. PIDiC $18: 0$ was investigated first and was mixed with $4 \%$ SA, $4 \%$ ML and $4 \% \mathrm{ML}+4 \% \mathrm{SA}$ (wt\%). DSC thermograms are given on Figure 7. The addition of $4 \%$ of ML did not induce any crystallization of the polymer and only the melting of the lipidic chain-ends was present. On the contrary, the addition of $4 \%$ SA or $4 \%$ ML $+4 \%$ SA favored CCr of the PI chains with a higher melting enthalpy when both free lipids were added, showing the synergetic effect of SA and ML. Moreover, the melting of SA can be observed at $48^{\circ} \mathrm{C}$. Nevertheless, even in the presence of $4 \%$ of both SA and ML, the overall crystallinity was much lower than that of NR. This is a different behavior than AE-NR for which addition of SA with ML allowed to recover the original cristallinity ${ }^{[19,20]}$. This can be due to a much higher weight content of linked fatty chains in our case as well as the low molar mass used for this study $(\sim 10000 \mathrm{~g} / \mathrm{mol})$. 


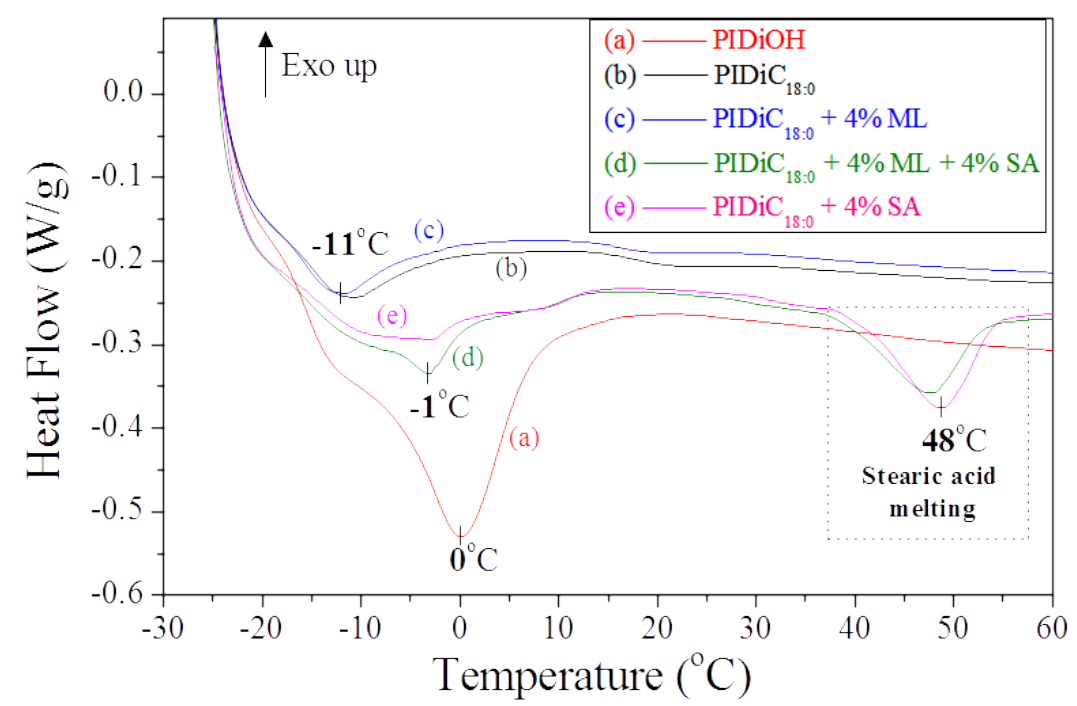

Figure 7: DSC thermograms of PIDiOH, PIDiC $C_{18: 0}$ and PIDiC $C_{18: 0}$ mixed with various amount of $M L$ and SA after isothermal crystallization at $-25^{\circ} \mathrm{C}$ for $8 \mathrm{~h}$

By mixing PIDiOH with $4 \%$ of SA $+4 \%$ of ML, it can be seen on Figure 8 that the addition of free fatty chains increased the crystallization rate which became even higher than the one of NR ( $t_{m}$ and $t_{f}$ of 91 and 182 min vs 146 and 338 min respectively) with an overall crystallinity comparable to the one of PIDiOH reported in

. It can be assumed that the nucleating effect of SA created the first nodules of crystallization and that the plasticizing capacity of ML conferred mobility to the chains even at low temperature. 


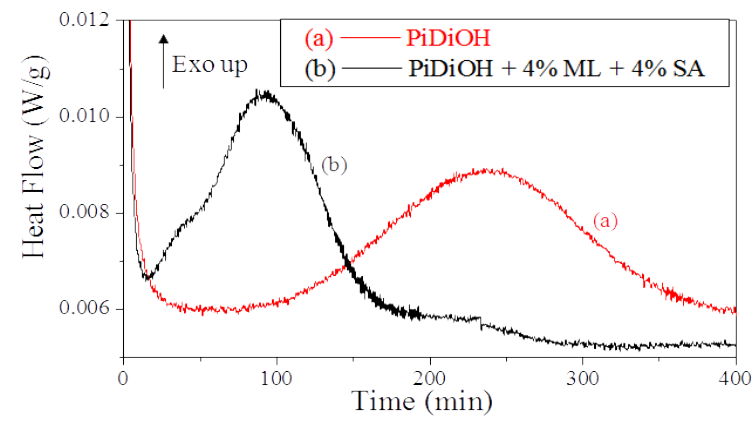

Figure 8: Isothermal crystallization study of a PIDiOH alone and with $4 \% M L+4 \%$ SA after isothermal crystallization at $-25^{\circ} \mathrm{C}$ for $8 \mathrm{~h}$

A similar study was also performed with a high molar mass IR ( $\left.\mathrm{M}_{\mathrm{n}} \sim 600000 \mathrm{~g} / \mathrm{mol}\right)$ having high content of 1,4-cis units ( 97\%). The same chemical procedures were followed to synthesize again hybrid polymer $\left(\operatorname{IRDiC}_{18: 0}\right)$ with a molar mass of polyisoprene of 10000 $\mathrm{g} / \mathrm{mol}$. The chain-end crystallization occurred like for PIDiC ${ }_{18: 0}$ synthesized from NR (Figure S24). Nevertheless, contrarily to NR, no crystallization was observed for the IRDiOH (Figure S25), neither for the starting IR maintained at $-25^{\circ} \mathrm{C}$ for $8 \mathrm{~h}$. The time of isotherm was thus extended to $60 \mathrm{~h}$ and in this case crystallization appeared only for the initial IR (Figure S26) but not for IRDeg (Figure S27). These results suggest that the CCr of IR is much slower than the one of NR certainly due to the presence of 1,2- and 3,4-units in the microstructure but also that the higher the molar mass, the quicker the CCr. As expected, IRDiC ${ }_{18: 0}$ did not exhibit any crystallization in agreement with the absence of CCr for IRDeg. IRDeg and IRDiC 18:0 were then mixed with free lipids ( $4 \% \mathrm{ML}+4 \% \mathrm{SA}$ ) and maintained at $-25^{\circ} \mathrm{C}$ for $60 \mathrm{~h}$. The DSC thermograms obtained are reported in Figure 9. Both the $\mathrm{IRDiC}_{18: 0}$ and the IRDeg recovered a CCr. In the case of the hybrid, only a weak endotherm can be observed which is partially covered by the melting of the fatty chain-end. But, like in the case of PIDeg mixed with free lipids, the IRDeg exhibits a huge endotherm corresponding to the crystallization of 
the PI. Moreover, the size of the endotherm obtained in the case of IRDeg mixed with free lipids is even bigger than the one of the starting IR. Again, this confirms the boosting role of the free lipids for the crystallization of PI.

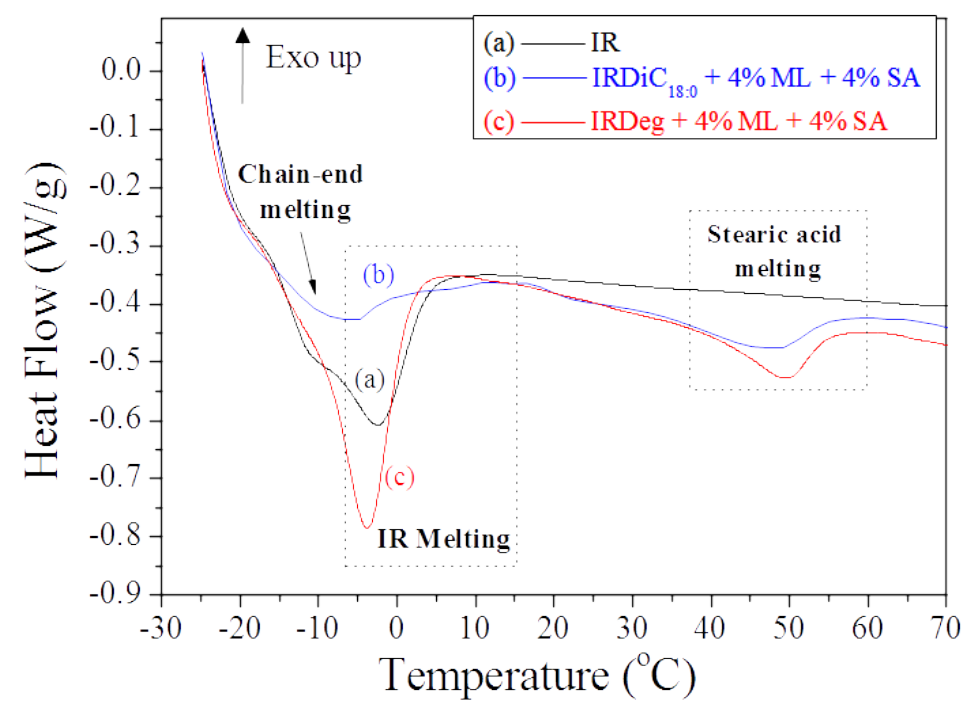

Figure 9: DSC thermograms of a high molar mass IR, IRDeg mixed with free fatty chains and IRDiC ${ }_{18: 0}$ also mixed with free fatty chains. Obtained after $60 \mathrm{~h}$ of crystallization at $-25^{\circ} \mathrm{C}$.

\section{Conclusion}

In this study, several hybrid polyisoprenes $\left(\mathrm{M}_{\mathrm{n}} \approx 10000 \mathrm{~g} / \mathrm{mol}\right)$ bearing one or two fatty chains at one chain-end were synthesized either from NR (100 \% 1,4-cis units) or from IR (97 \% 1,4cis units) as models of NR. Before the grafting of the fatty chain, polymers coming from NR exhibited a high crystallinity after isothermal treatment at $-25^{\circ} \mathrm{C}$, whereas polymers coming from IR showed no crystallinity probably due to the presence of other units than 1,4-cis. Detailed DSC analyses of the hybrid polymers showed that the grafting of lipidic chains prevented cold crystallization of polyisoprene, a general feature of NR. On the contrary, chain-ends could crystallize relatively quickly despite the huge amorphous matrix. The addition of free fatty acids to the hybrid polymer allowed to recover a partial cold crystallization in a lower amount than the initial NR. Nevertheless, addition of both SA and 
ML presented a synergetic effect to enhance CCr of all the polymers either natural or synthetic. All these observations allow to clarify the role of both free and linked fatty chains on the CCr of NR and allowed to obtain a crystallization rate of a $10000 \mathrm{~g} / \mathrm{mol}$ IR comparable to the one of a $600000 \mathrm{~g} / \mathrm{mol} \mathrm{IR}$.

These results open new perspectives for synthetic chemists as it seems to be possible to synthesize elastomers of low molar mass that could mimic the properties of NR (of very high molar mass) that are generally far to be reached by regular synthetic elastomers.

\section{Supporting Information}

Supporting Information is available from the Wiley Online Library or from the author 


\section{REFERENCES}

[1] S. Kohjiya, Y. Ikeda, Eds. , Chemistry, Manufacture and Applications of Natural Rubber, Elsevier/Woodhead Publ, Amsterdam, 2014.

[2] A. N. Gent, S. Kawahara, J. Zhao, Rubber Chem. Technol. 1998, 71, 668-678.

[3] S. Trabelsi, P.-A. Albouy, J. Rault, Rubber Chem. Technol. 2004, 77, 303-316.

[4] S. Toki, B. S. Hsiao, S. Amnuaypornsri, J. Sakdapipanich, Polymer 2009, 50, $2142-$ 2148.

[5] E. C. Gregg, Rubber Chem. Technol. 1973, 47-66.

[6] J. M. Chenal, L. Chazeau, Y. Bomal, C. Gauthier, J. Polym. Sci. Part B Polym. Phys. 2007, 45, 955-962.

[7] Y. Tanaka, L. Tarachiwin, Rubber Chem. Technol. 2009, 82, 283-314.

[8] Y. Tanaka, Rubber Chem. Technol. 2001, 74, 355-375.

[9] L. Tarachiwin, J. Sakdapipanich, K. Ute, T. Kitayama, T. Bamba, E. Fukusaki, A. Kobayashi, Y. Tanaka, Biomacromolecules 2005, 6, 1851-1857.

[10] L. Tarachiwin, J. Sakdapipanich, K. Ute, T. Kitayama, Y. Tanaka, Biomacromolecules 2005, 6, 1858-1863.

[11] L. Wood, J. Appl. Phys. 1946, 17, 362-375.

[12] D. R. Burfield, Polymer 1984, 25, 1823-1826.

[13] S. Kawahara, T. Kakubo, J. T. Sakdapipanich, Y. Isono, Y. Tanaka, Polymer 2000, 41, 7483-7488.

[14] E. Aik-Hwee, S. Kawahara, Y. Tanaka, J. Appl. Polym. Sci. Appl. Polym. Symp. 1994, 53, 5-14.

[15] S. Kawahara, K. Takano, J. Yunyongwattanakorn, Y. Isono, M. Hikosaka, J. T. Sakdapipanich, Y. Tanaka, Polym. J. 2004, 36, 361-367.

[16] S. Kawahara, Y. Tanaka, J. Polym. Sci. Part B Polym. Phys. 1995, 33, 753-758. 
[17] A. N. Gent, S. Kawahara, J. Zhao, Rubber Chem. Technol. 1998, 71, 668-678.

[18] T. Kakubo, A. Matsuura, S. Kawahara, Y. Tanaka, Rubber Chem. Technol. 1998, 71, $70-75$.

[19] S. Kawahara, Rubber Chem. Technol. 1996, 69, 600-607.

[20] S. Kawahara, T. Kakubo, J. T. Sakdapipanich, Y. Isono, Y. Tanaka, Polymer 2000, 41, 7483-7488.

[21] S. Kawahara, Rubber Chem. Technol. 1990, 69, 608-614.

[22] D. R. Burfield, Y. Tanaka, Polymer 1987, 28, 907-910.

[23] S. Ouardad, A. Deffieux, F. Peruch, Pure Appl. Chem. 2012, 84, DOI 10.1351/PACCON-12-02-05.

[24] I. V. Vasilenko, H. Y. Yeong, M. Delgado, S. Ouardad, F. Peruch, B. Voit, F. Ganachaud, S. V. Kostjuk, Angew. Chem. 2015, 127, 12919-12923.

[25] H. L. Hsieh, R. P. Quirk, Anionic Polymerizati 
[33] T. T. Tidwell, Ketenes, John Wiley \& Sons, 2006.

[34] A. F. Abdel-Magid, S. J. Mehrman, Org. Process Res. Dev. 2006, 10, 971-1031.

[35] S. Liengprayoon, J. Chaiyut, K. Sriroth, F. Bonfils, J. Sainte-Beuve, E. Dubreucq, L. Vaysse, Eur. J. Lipid Sci. Technol. 2013, 115, 1021-1031. 
((Supporting Information should be included here for submission only; for publication, please provide Supporting Information as a separate PDF file.))

Copyright WILEY-VCH Verlag GmbH \& Co. KGaA, 69469 Weinheim, Germany, 2013.

\section{Supporting Information}

for Macromol. Chem. Phys, DOI: 10.1002/macp.2013\#\#\#\#\#

New Insight into the Cold Crystallization of Natural Rubber: The role of linked and free fatty chains

Jérémie Grange $^{\mathrm{a}, \mathrm{b}}$, Alexei V. Radchenko ${ }^{\mathrm{a}}$, Rachid Matmour ${ }^{\mathrm{b}}$, François Jean-Baptiste dit Dominique $^{\mathrm{b}}$, Stéphane Grelier ${ }^{\mathrm{a}}$, Frédéric Peruch ${ }^{\mathrm{a} *}$

${ }^{a}$ Univ. Bordeaux, CNRS, Bordeaux INP/ENSCBP, Laboratoire de Chimie des Polymères Organiques, UMR 5629, 16 avenue Pey-Berland, F-33607 Pessac Cedex, France

${ }^{\mathrm{b}}$ Manufacture Française des Pneumatiques Michelin, Z.I. Ladoux, F-63040 Clermont-Ferrand Cedex 9, France

*E-mail: peruch@enscbp.fr 


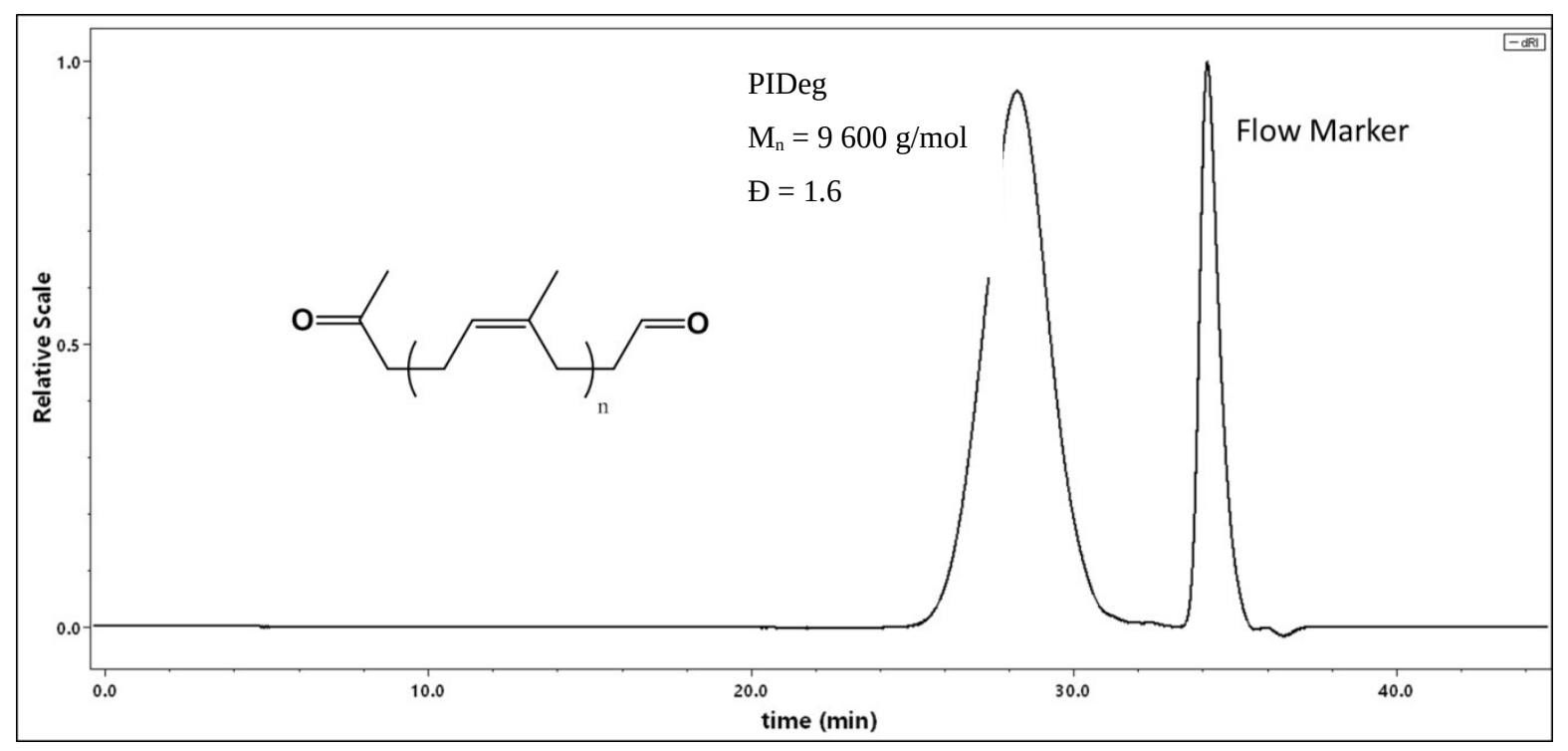

Figure S1: SEC chromatogram of PiDeg

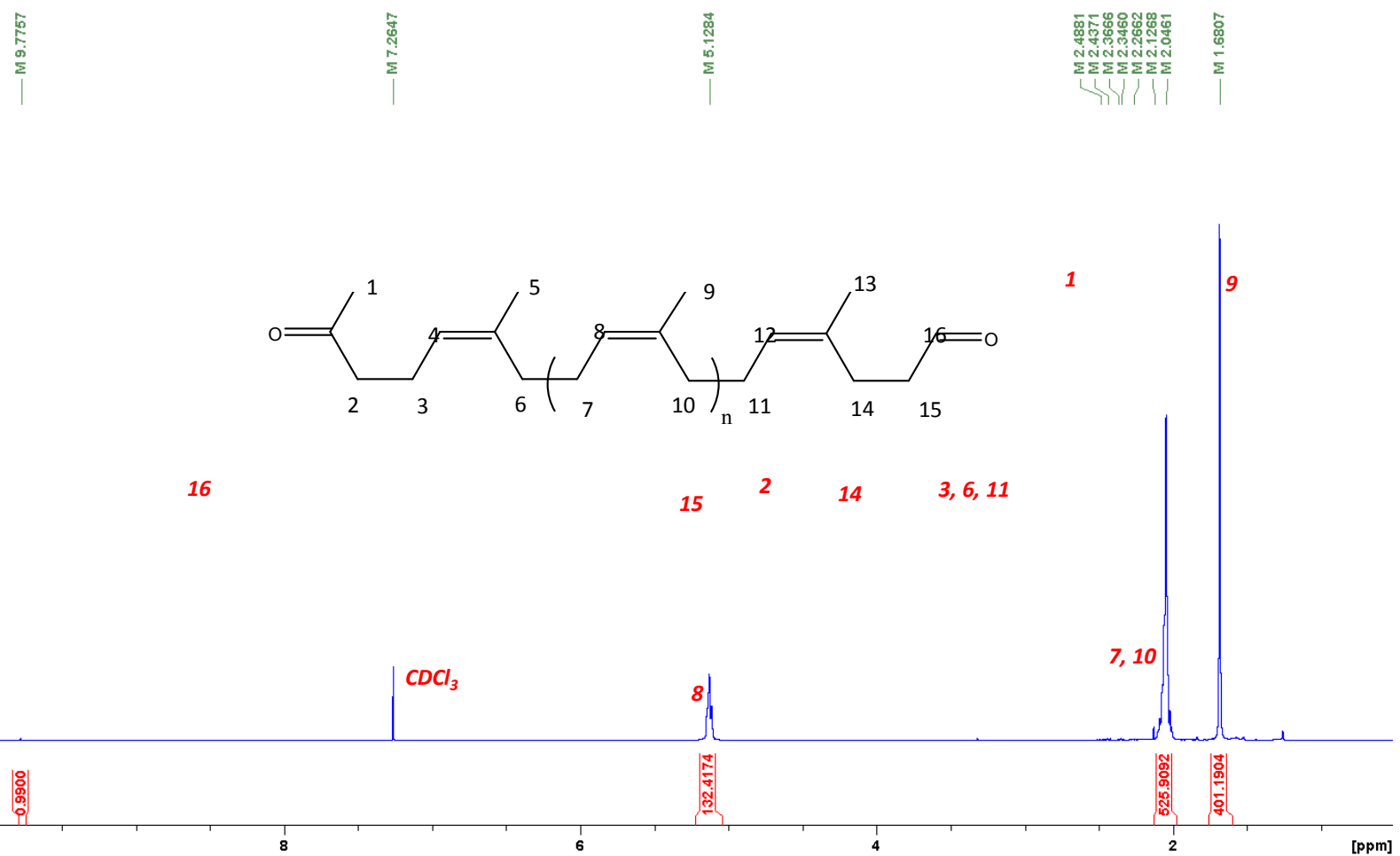

Figure S2: ${ }^{1} \mathrm{H}$ NMR spectrum of PIDeg in $\mathrm{CDCl}_{3}$ 
O

0

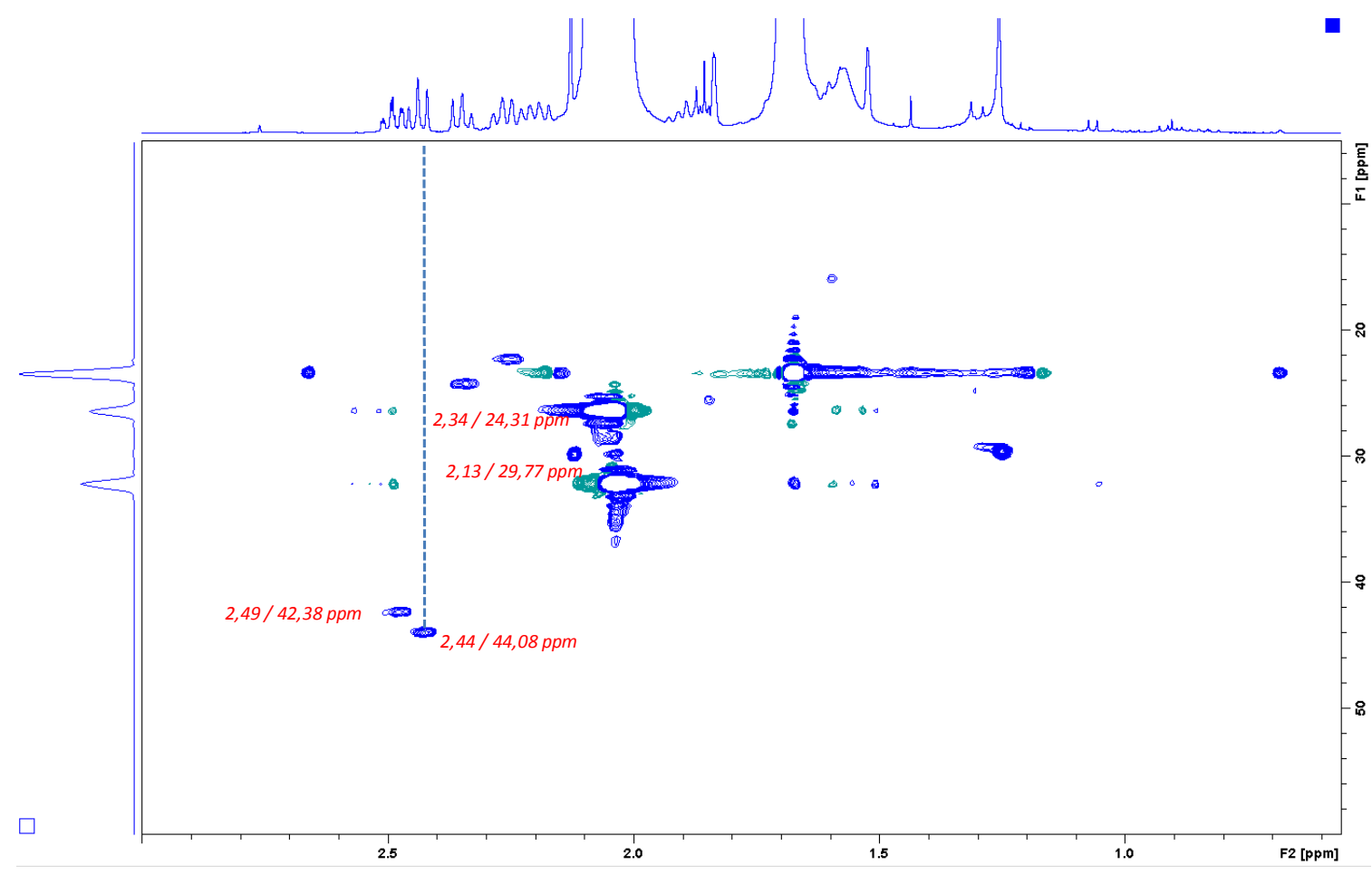

Figure S3: 2D NMR spectrum (HSQC) of PIDeg in $\mathrm{CDCl}_{3}$

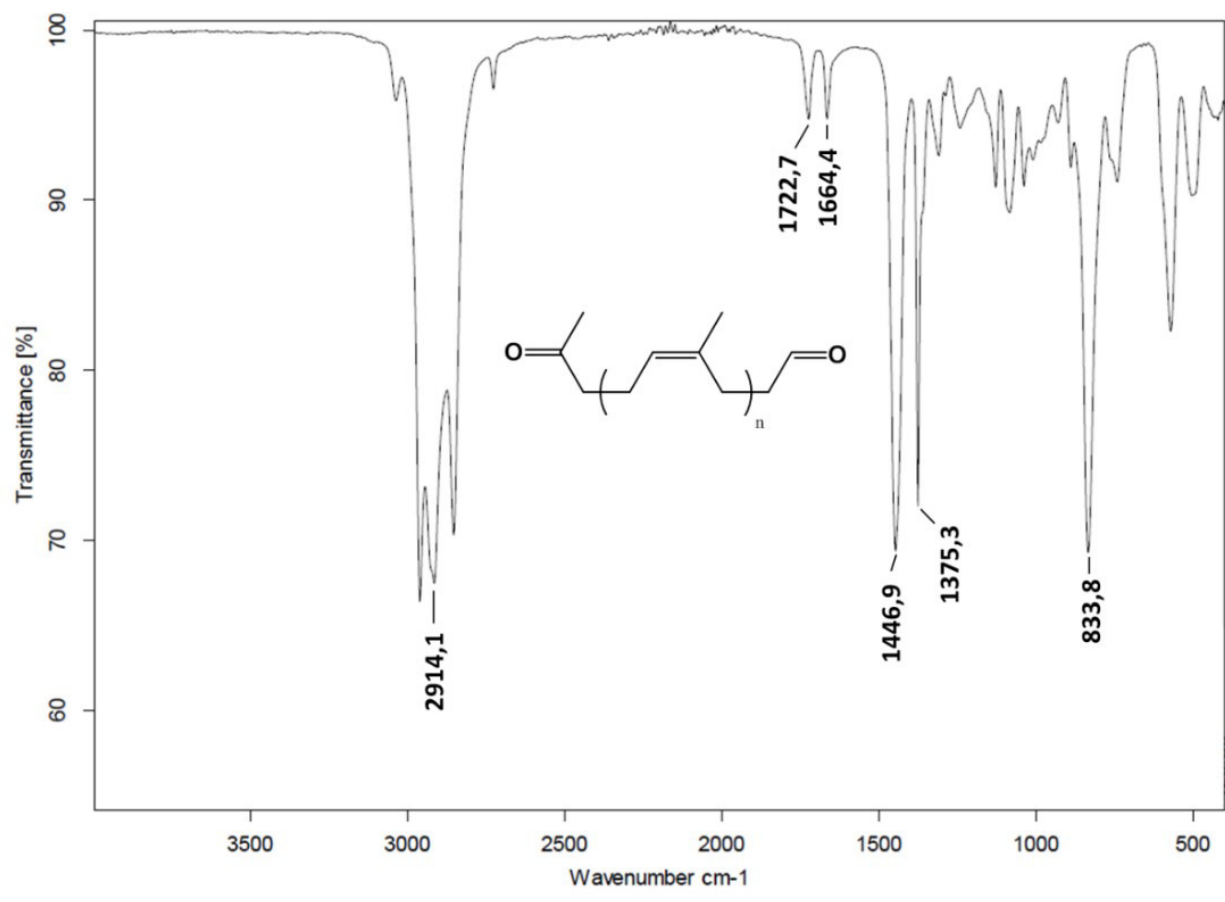

Figure S4: ATR-FTIR spectrum of PIDeg 


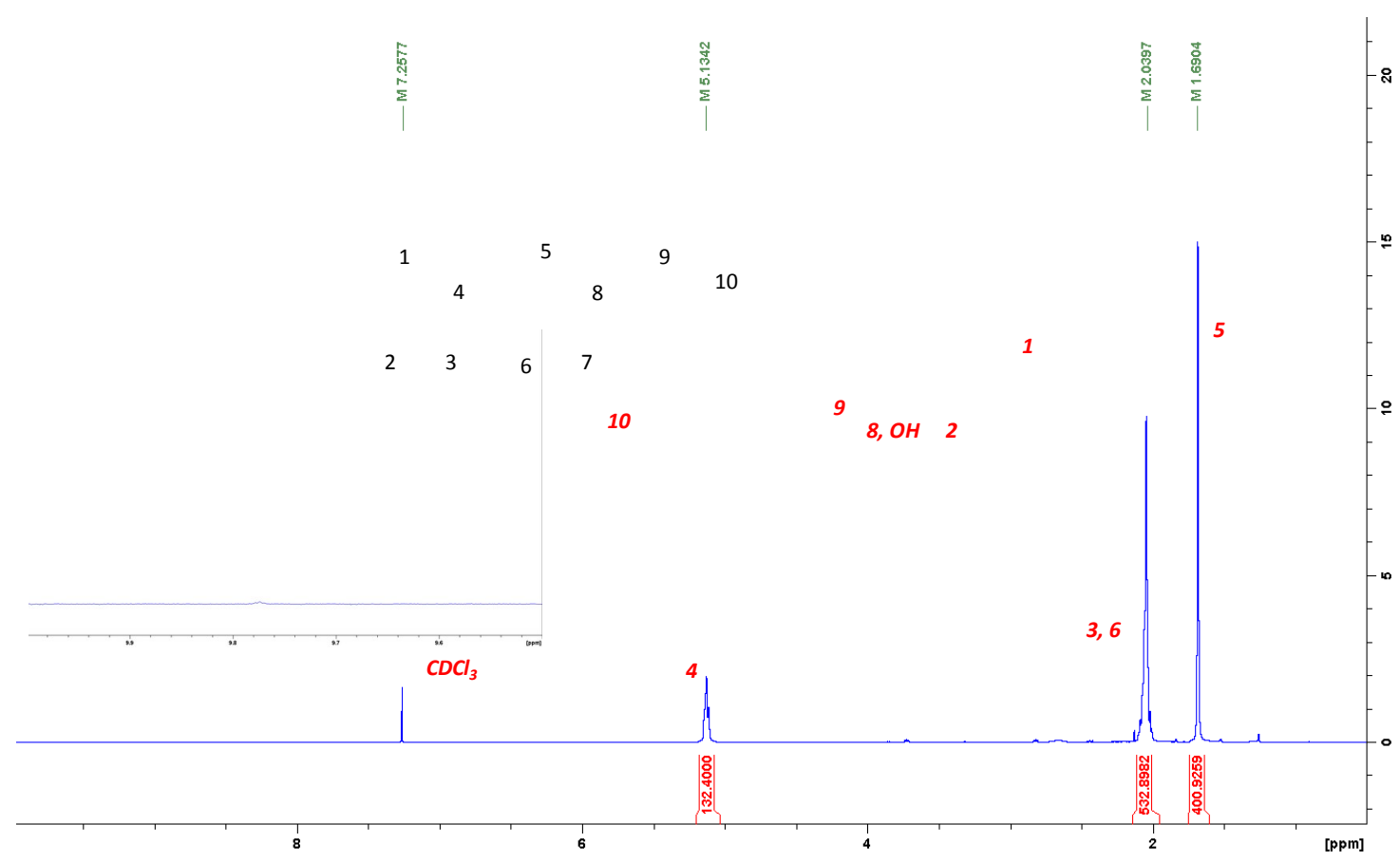

Figure S5: ${ }^{1} \mathrm{H}$ NMR spectrum of $\mathrm{PIDiOH}$ in $\mathrm{CDCl}_{3}$

$2,13 / 30,27 p p m$

$\mathrm{O}$

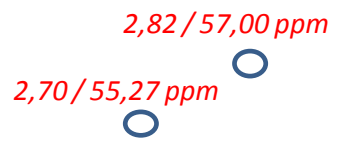

O

$2,44 / 44,27 p p m$

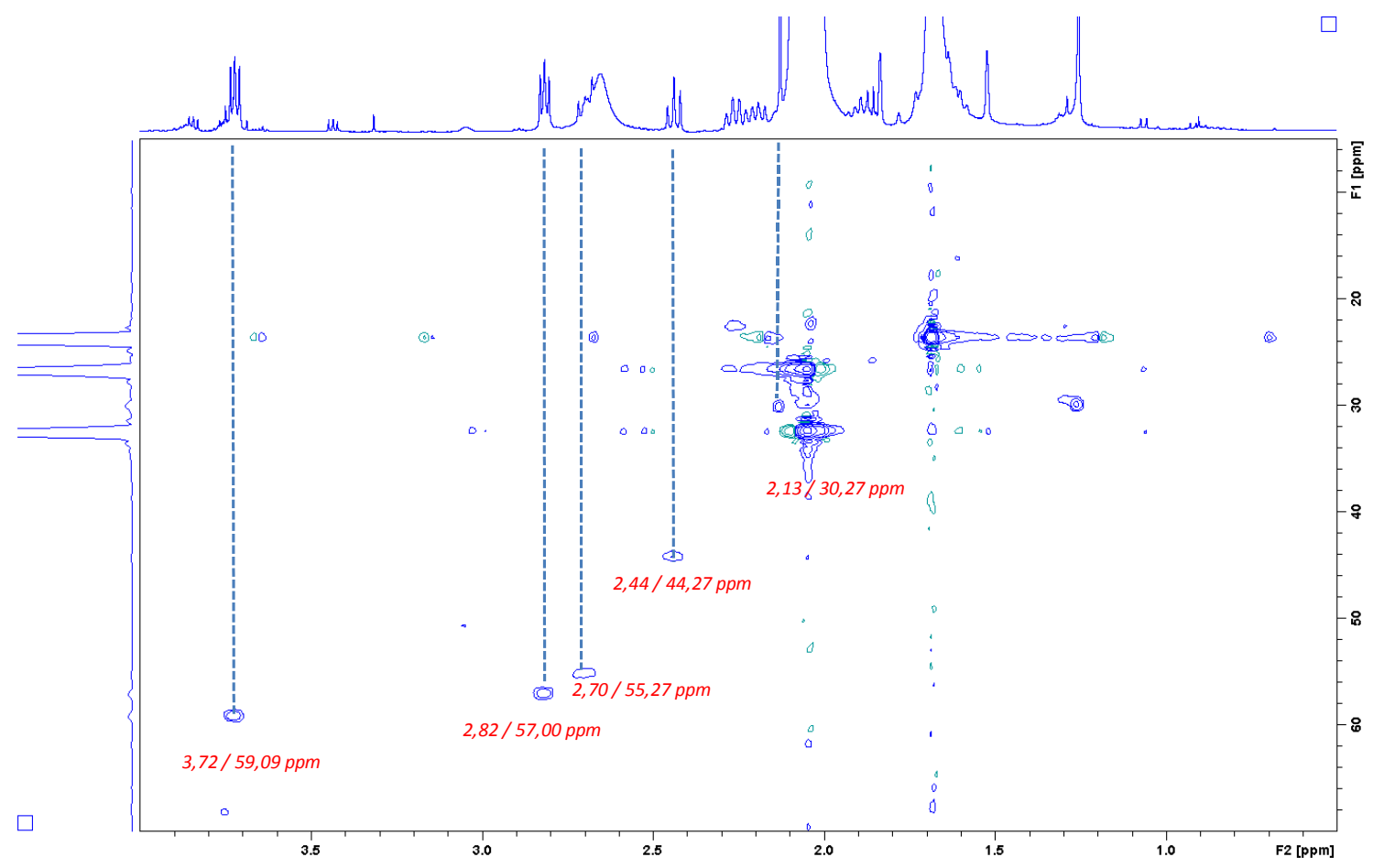

Figure S6: 2D NMR spectrum (HSQC) of PIDiOH in $\mathrm{CDCl}_{3}$ 


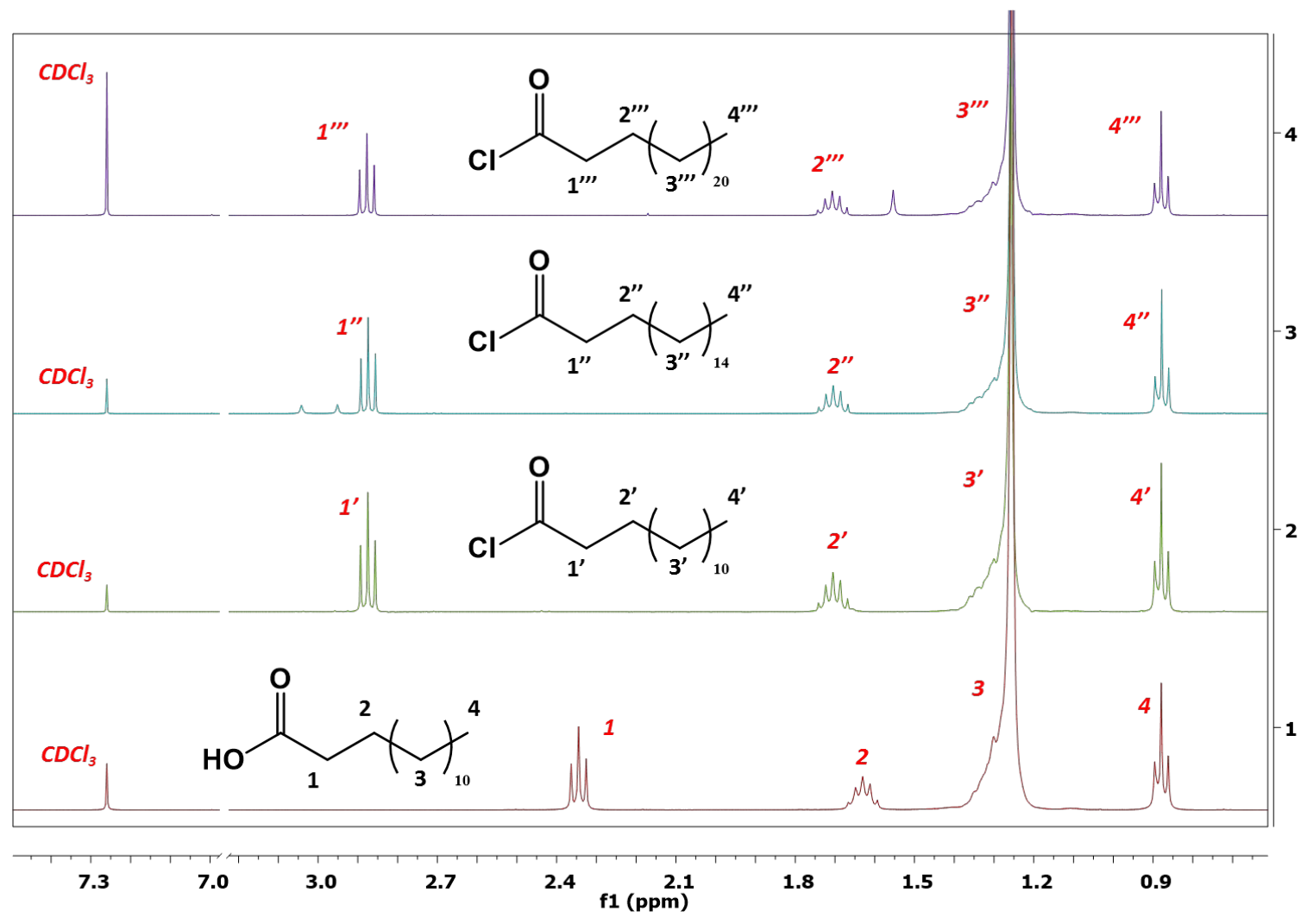

Figure S7: ${ }^{1} \mathrm{H}$ NMR spectra of myristic acid, $C_{14: 0}$ Chlo, $C_{18: 0}$ Chlo and $C_{24: 0} C h l o$ in $\mathrm{CDCl}_{3}$

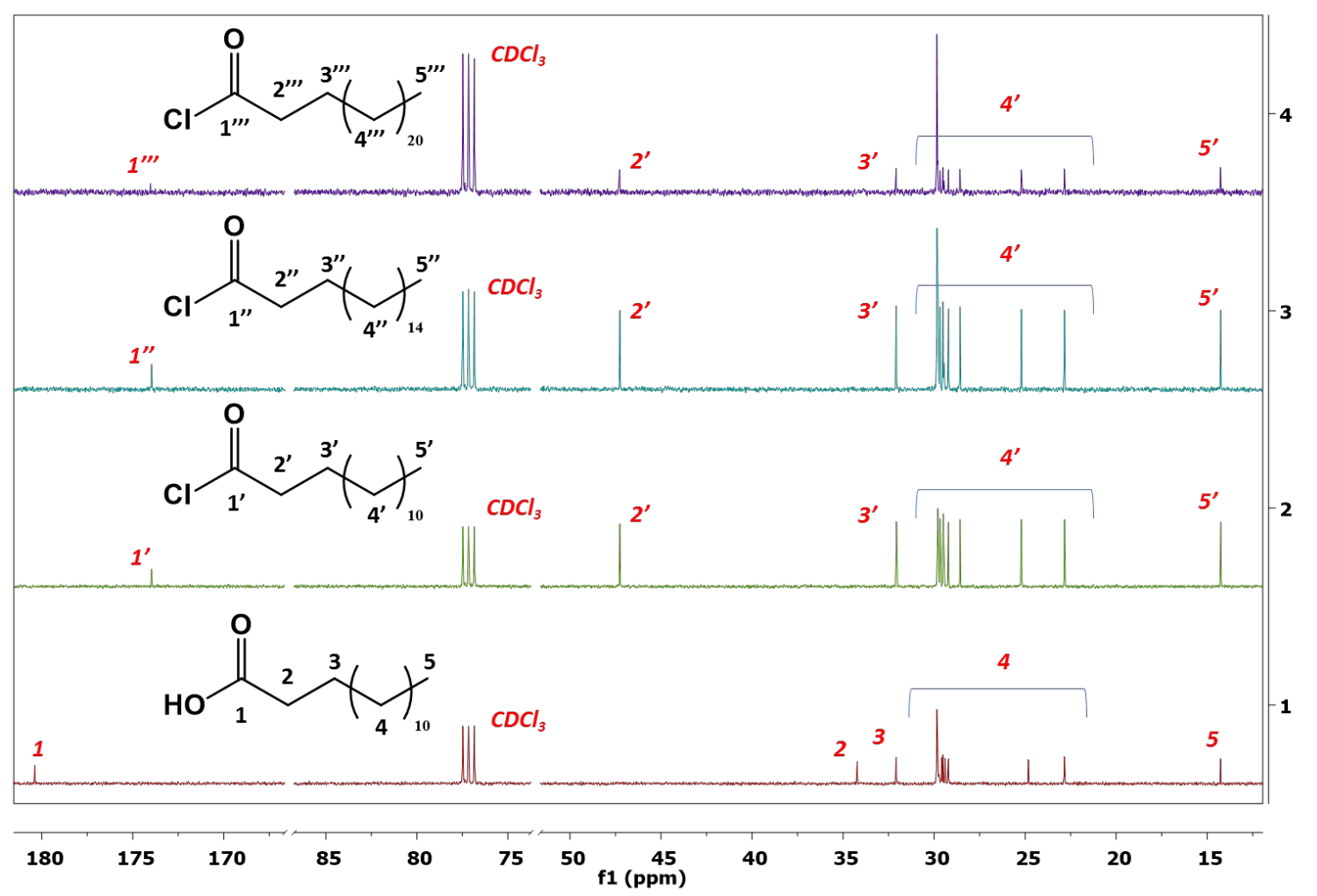

Figure S8: ${ }^{13} \mathrm{C}$ NMR spectra of myristic acid, $C_{14: 0}$ Chlo, $C_{18: 0}$ Chlo and $C_{24: 0}$ Chlo in $\mathrm{CDCl}_{3}$ 


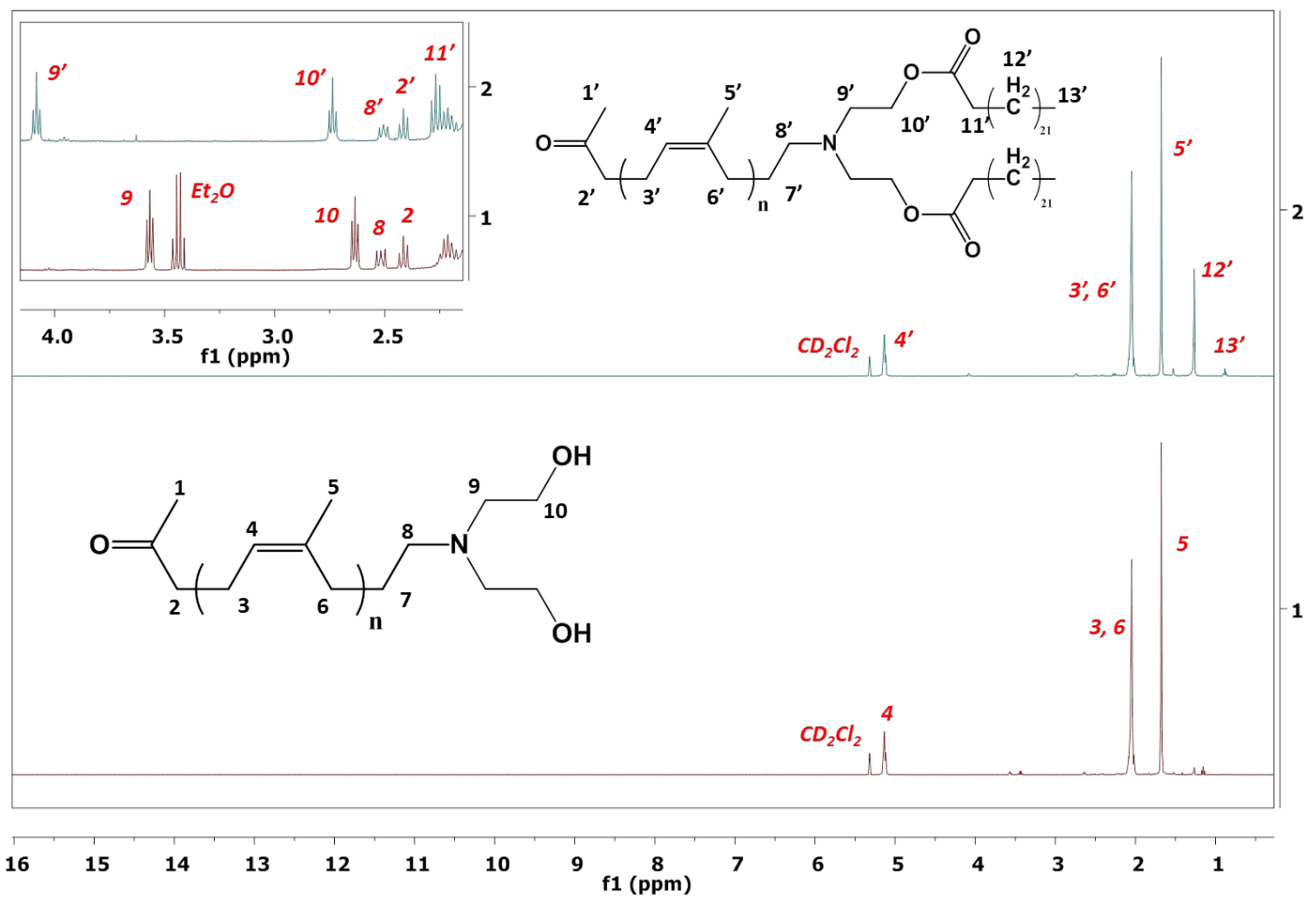

Figure S9: ${ }^{1} \mathrm{H}$ NMR spectra of PIDiOH and PIDiC $\mathrm{C}_{24: 0}$ in $\mathrm{CD}_{2} \mathrm{Cl}_{2}$

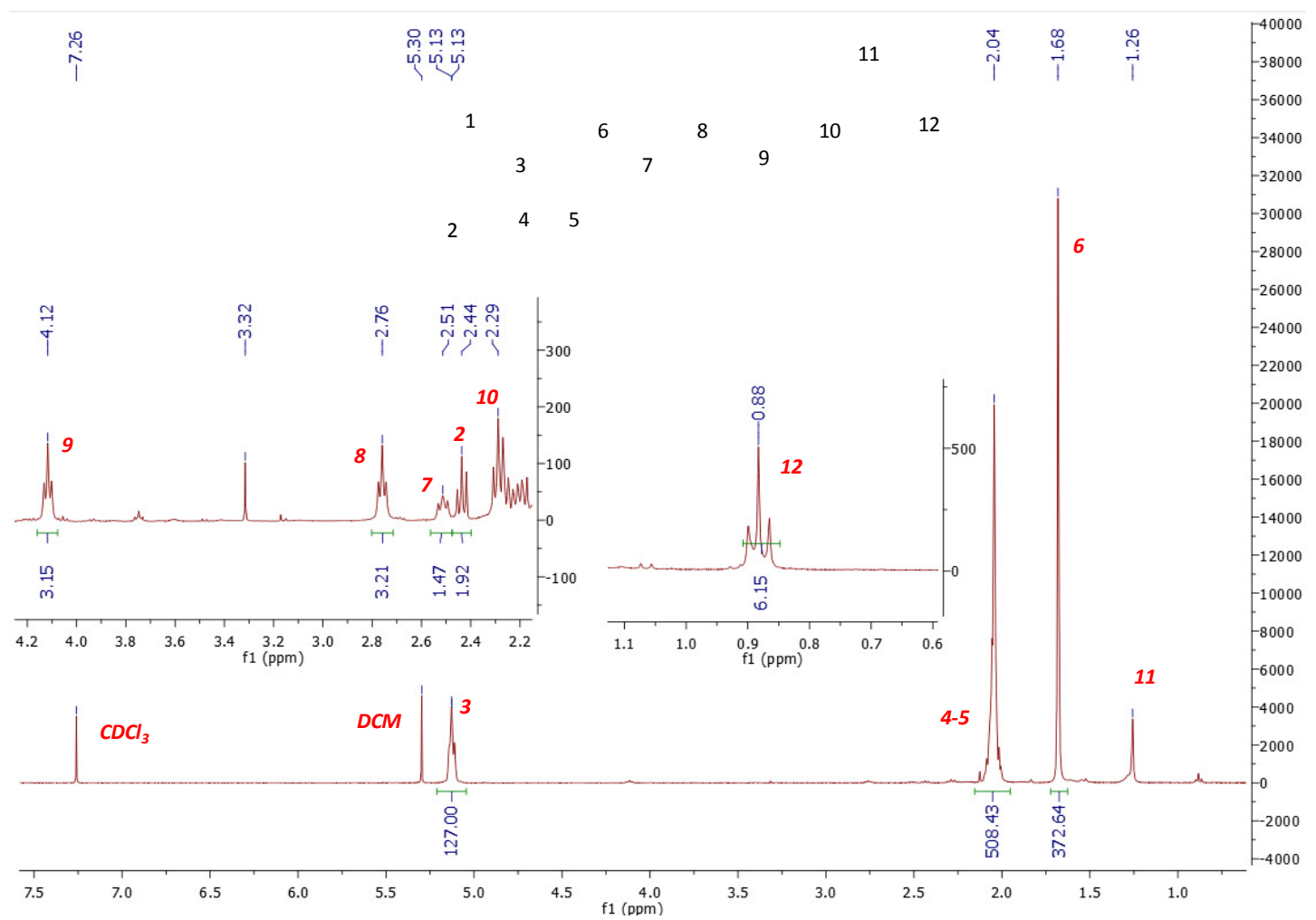

Figure S10: ${ }^{1} \mathrm{H}$ NMR spectrum of $\mathrm{PIC}_{16: 0}$ in $\mathrm{CD}_{2} \mathrm{Cl}_{2}$ 


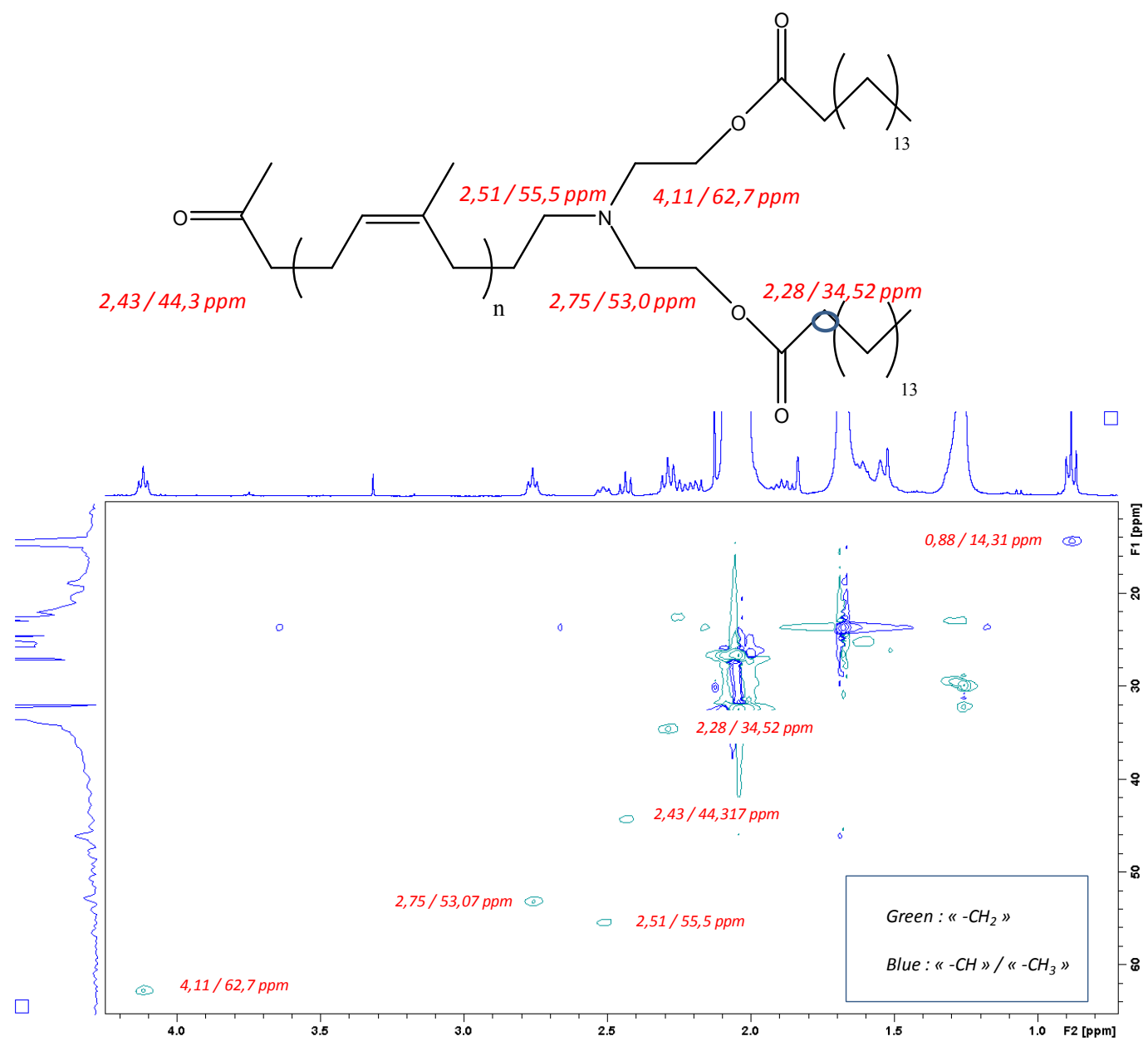

Figure S11: 2D NMR (HSQC DEPT) spectrum of $\mathrm{PIC}_{16: 0}$ in $\mathrm{CD}_{2} \mathrm{Cl}_{2}$

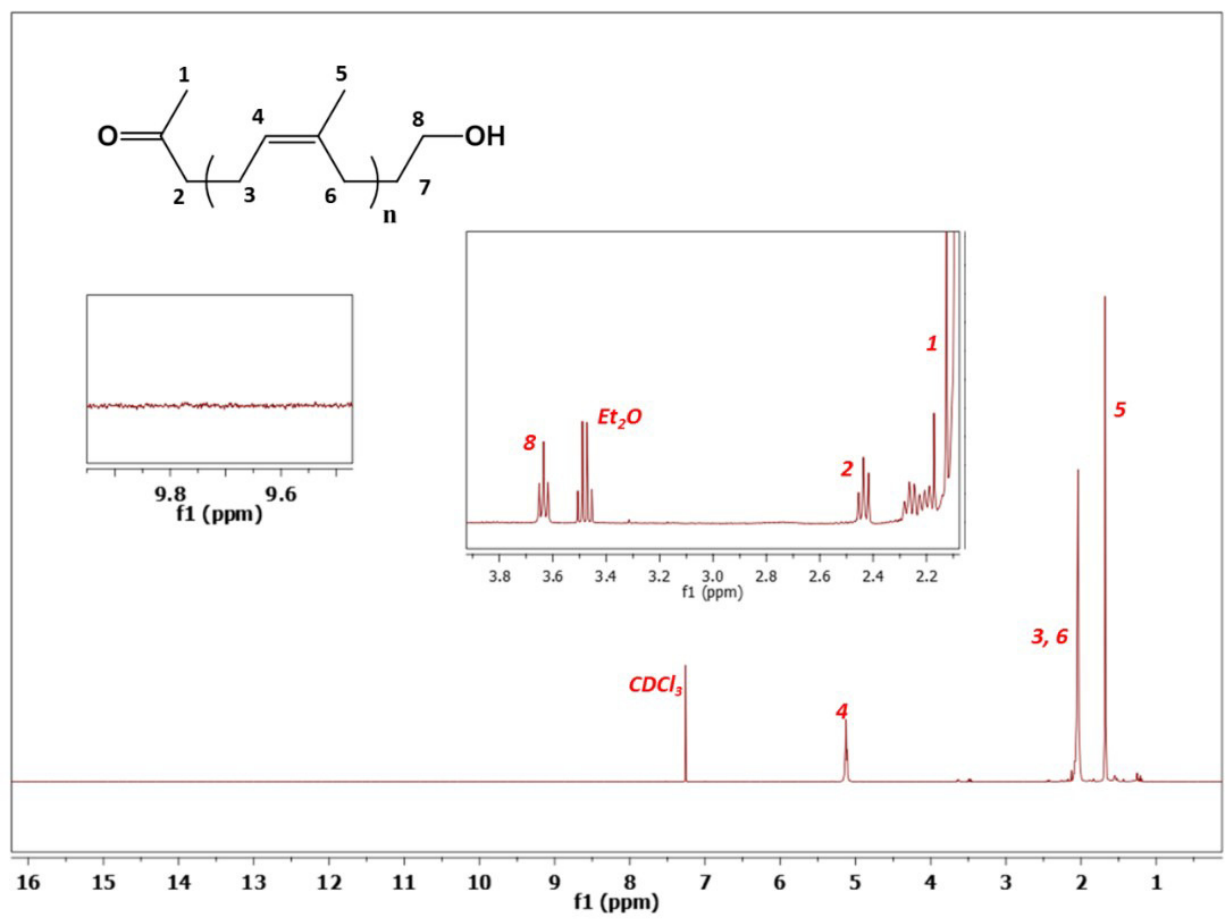

Figure S12: ${ }^{1} \mathrm{H}$ NMR spectrum of $\mathrm{PIOH}$ in $\mathrm{CDCl}_{3}$ 


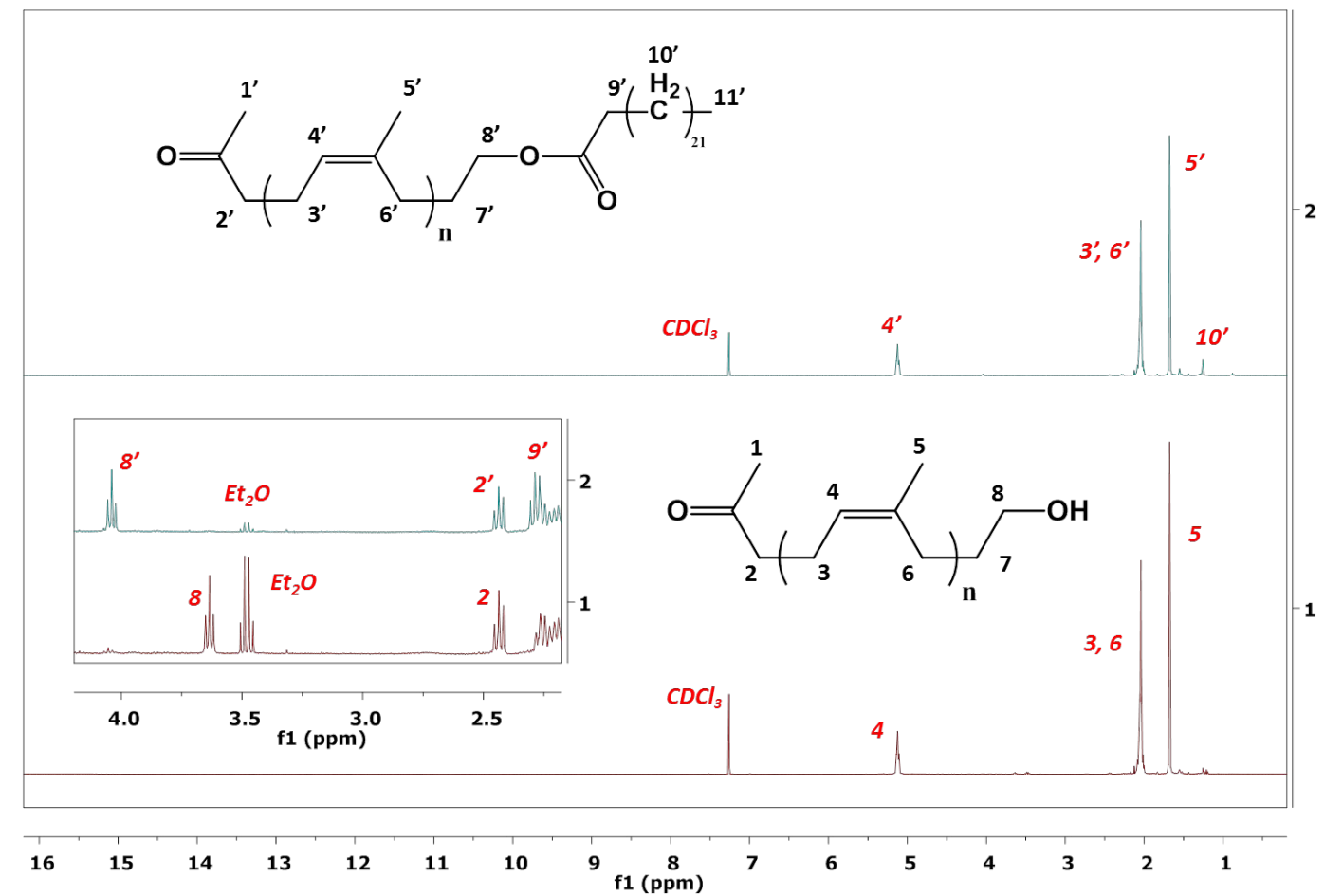

Figure S13: ${ }^{1} \mathrm{H}$ NMR spectra of PIMonoOH and PIMonoC $\mathrm{PI:0}_{2}$ in $\mathrm{CDCl}_{3}$

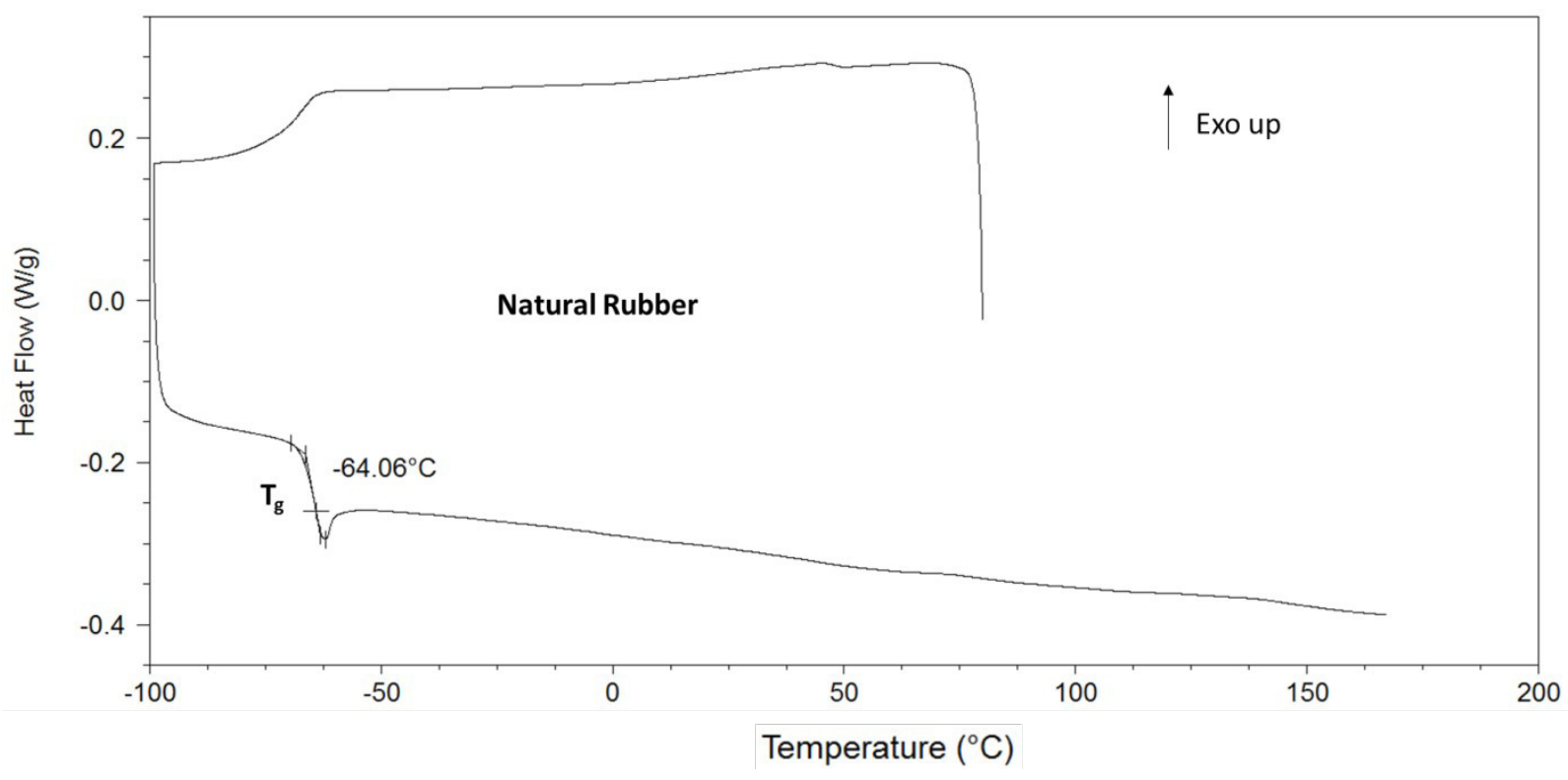

Figure S14: DSC thermogram of NR 


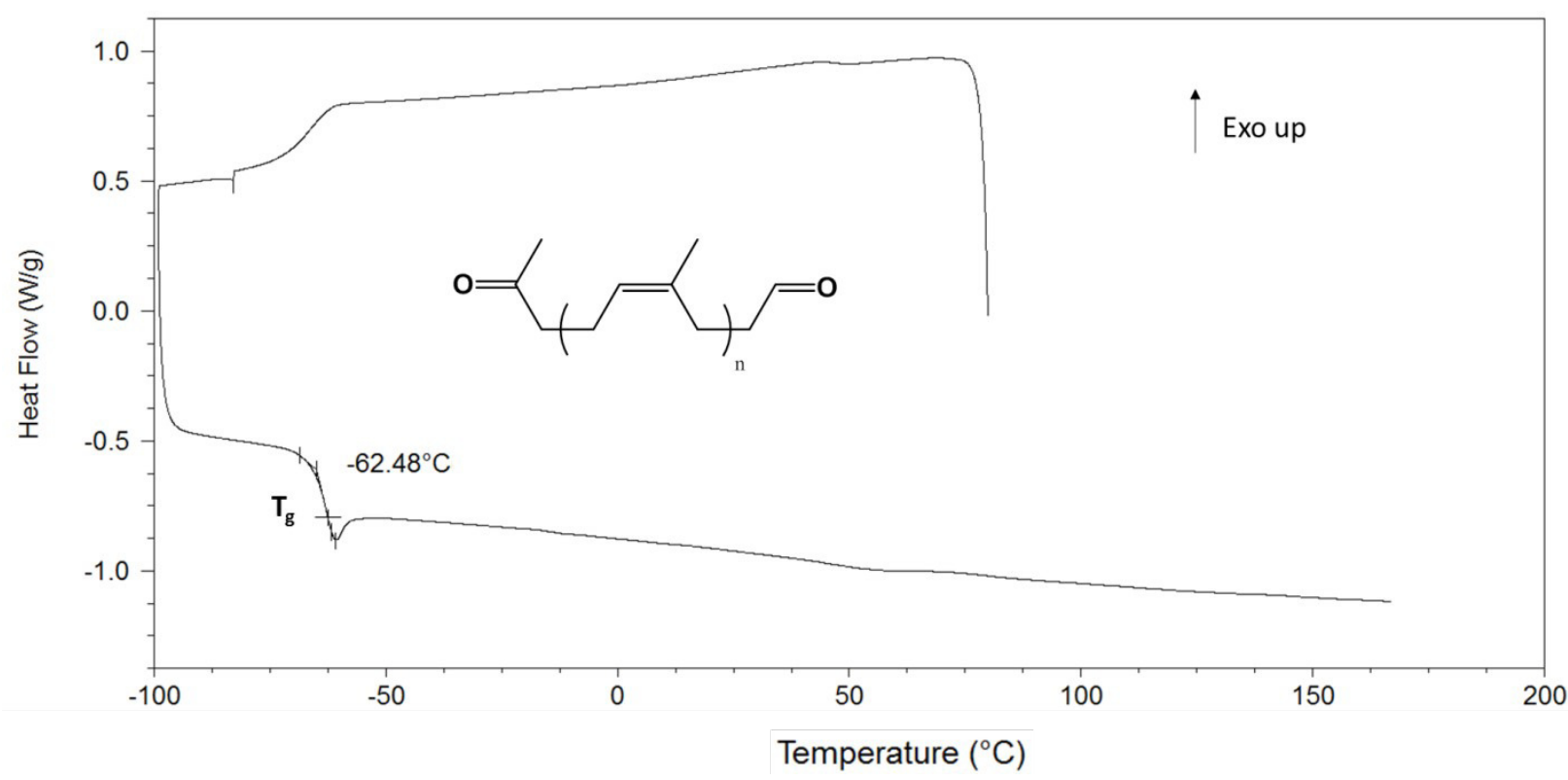

Figure S15: DSC thermogram of PIDeg

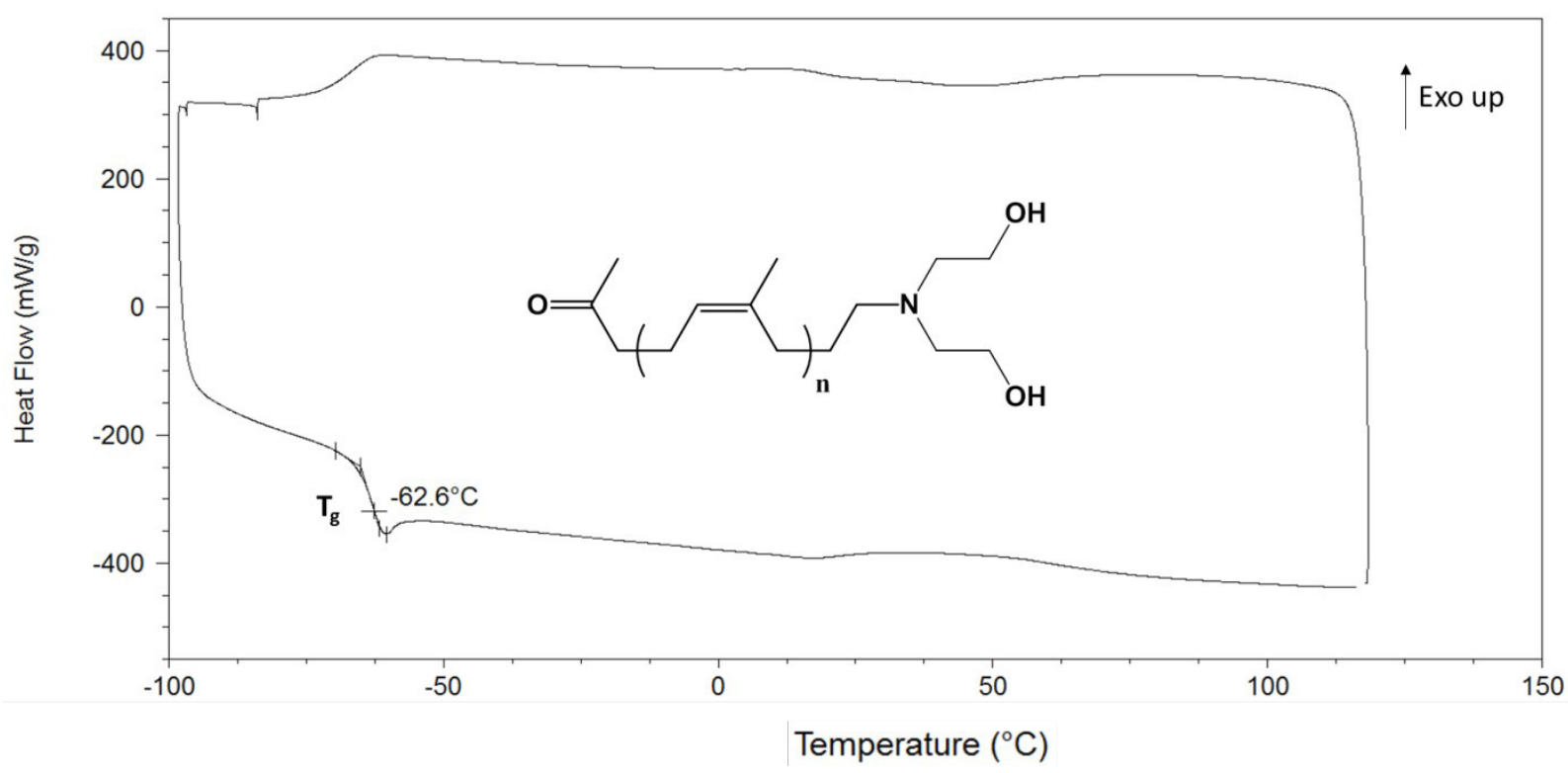

Figure S16: DSC thermogram of PIDiOH 


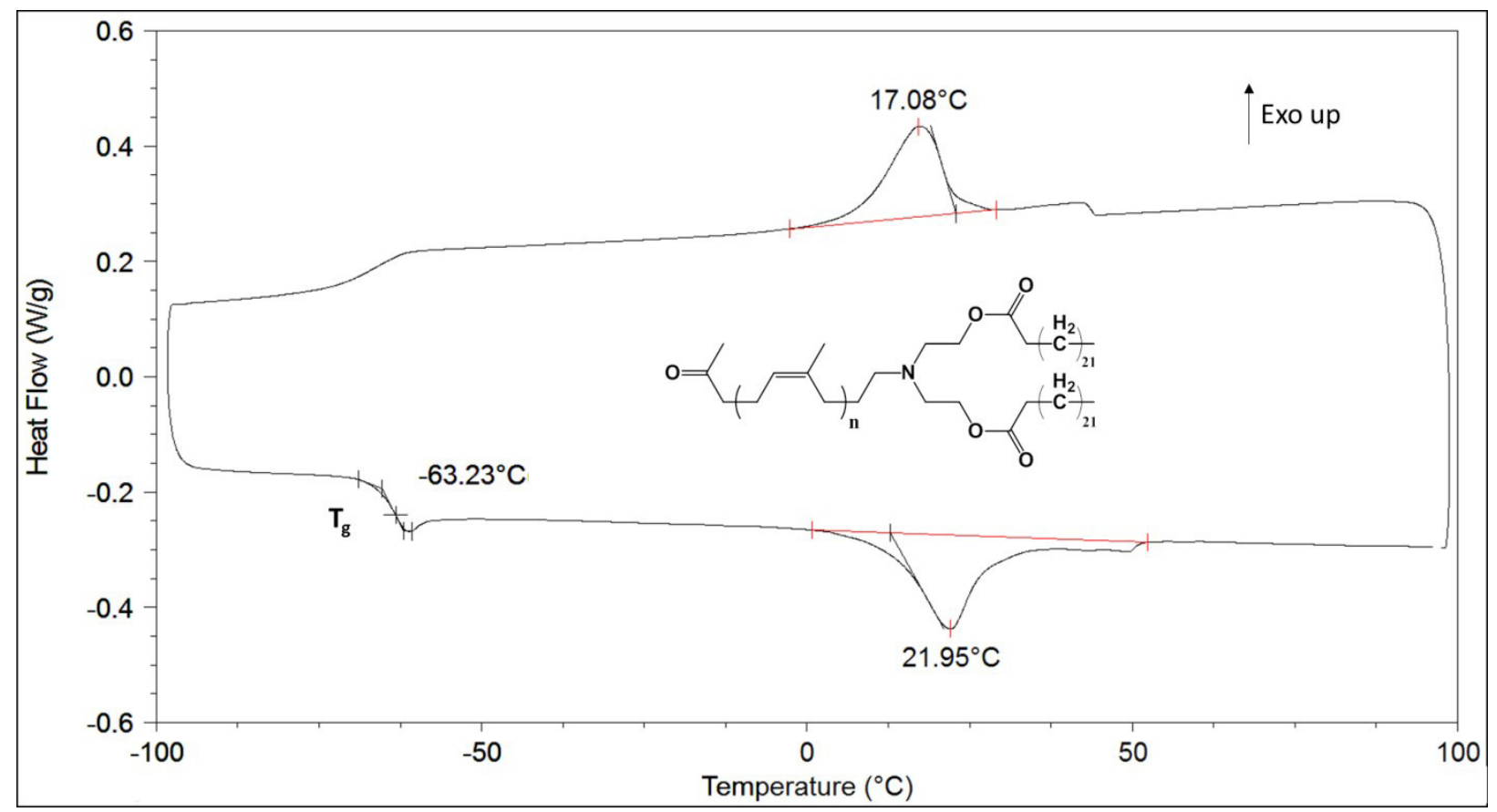

Figure S17: DSC thermogram of PIDiC $_{24: 0}$

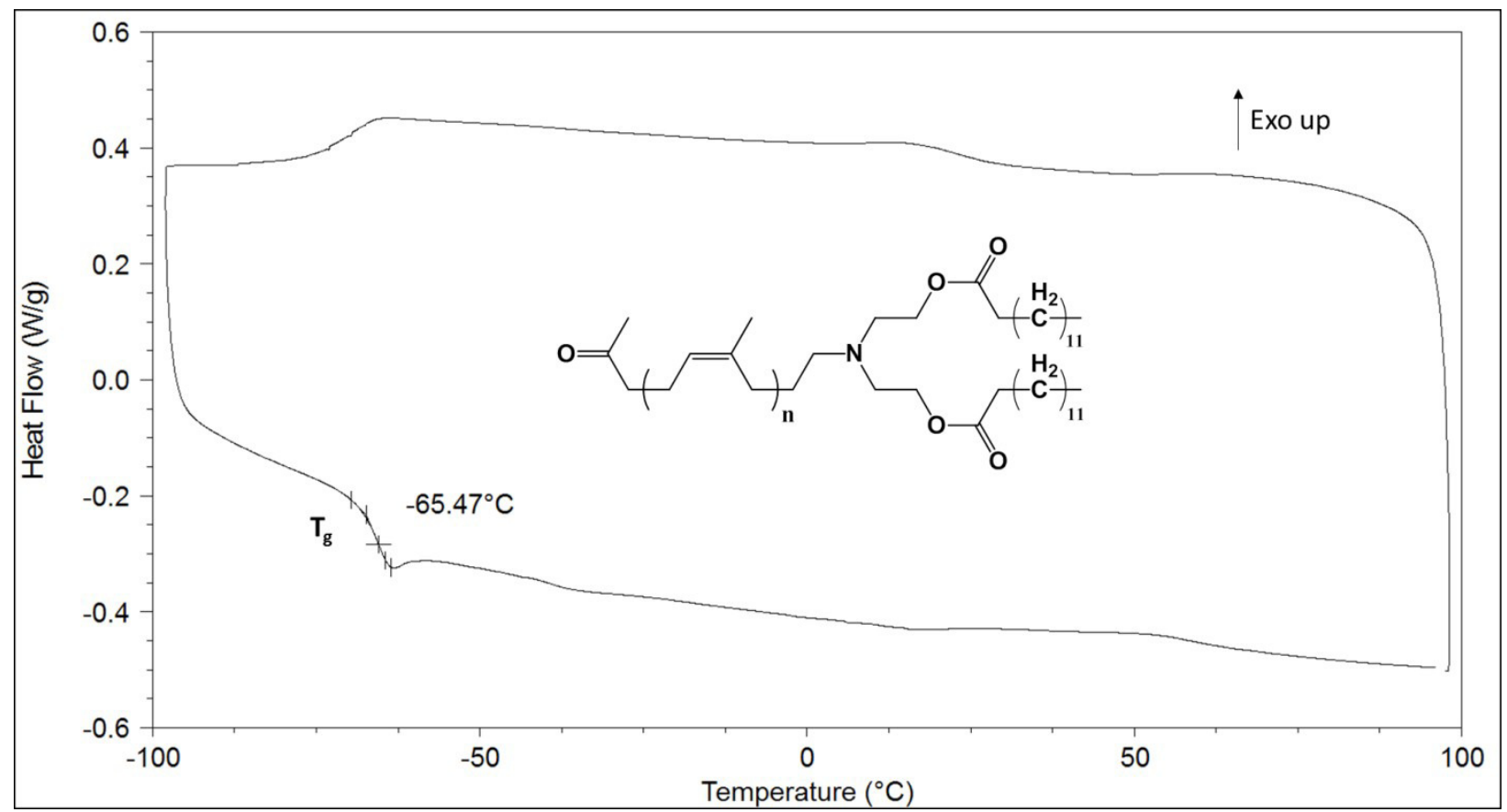

Figure S18: DSC thermogra of PIDiC ${ }_{14: 0}$ 


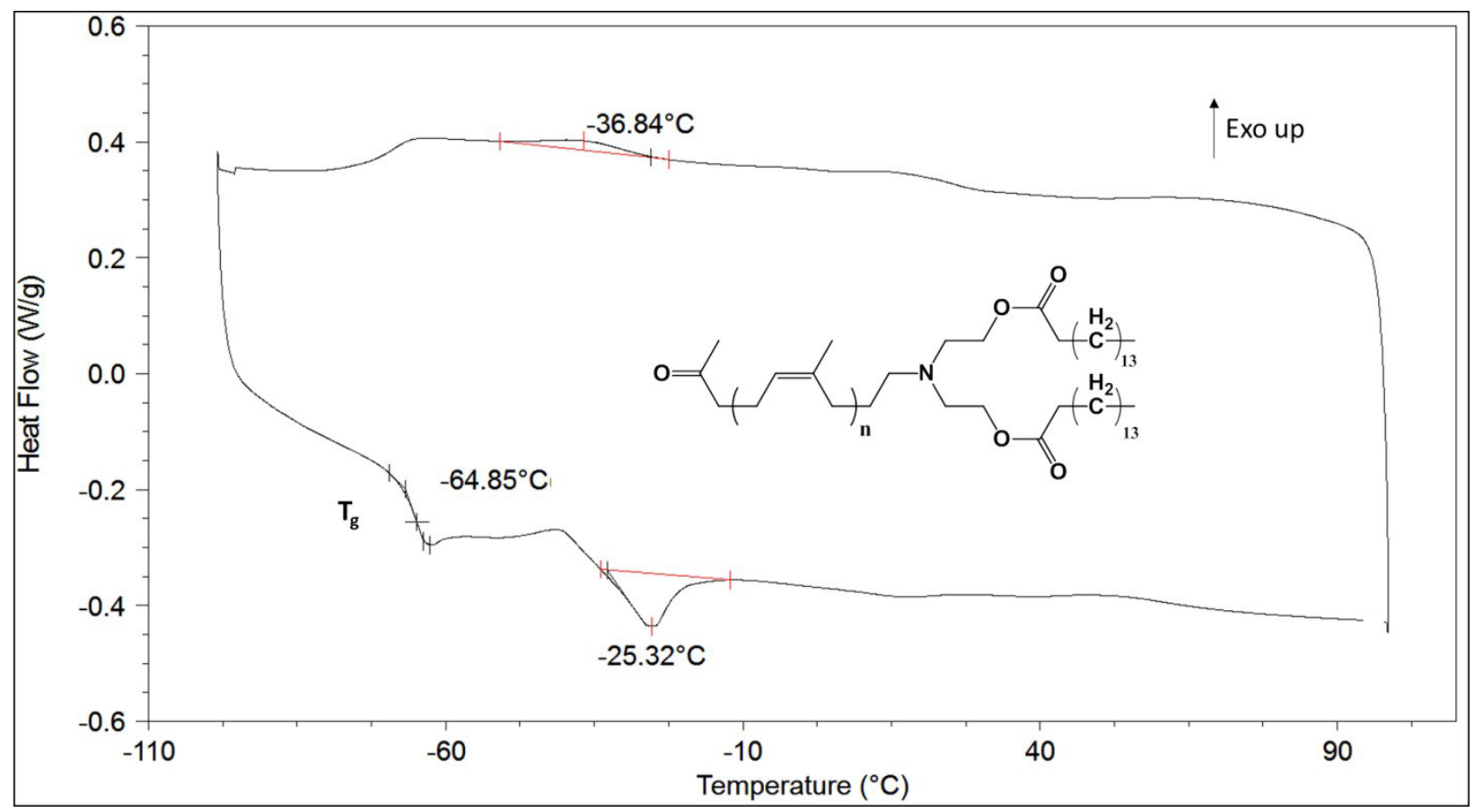

Figure S19: DSC thermogra of PIDiC ${ }_{16: 0}$

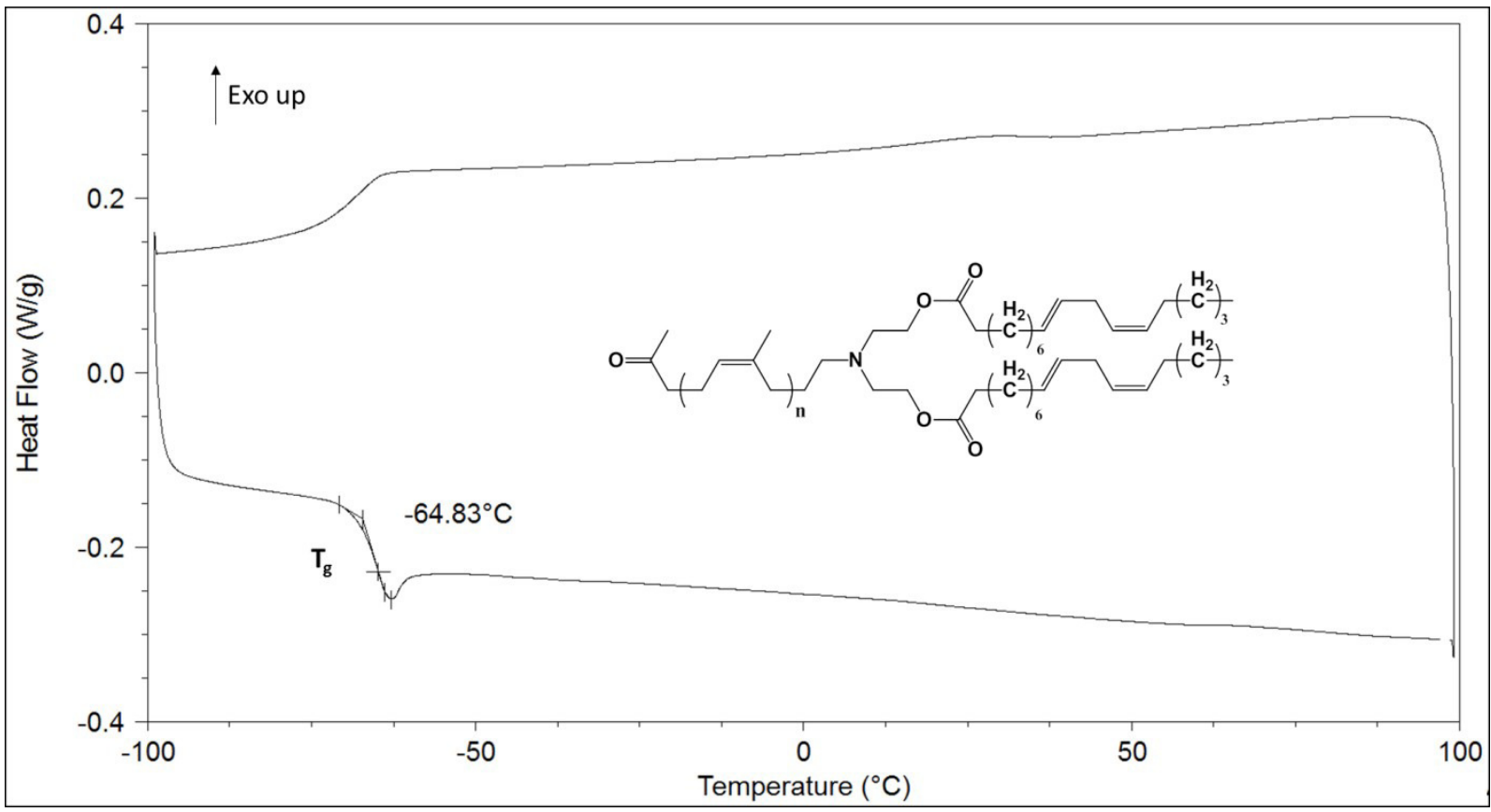

Figure S20: DSC thermogram of PIDiC ${ }_{18: 2}$ 


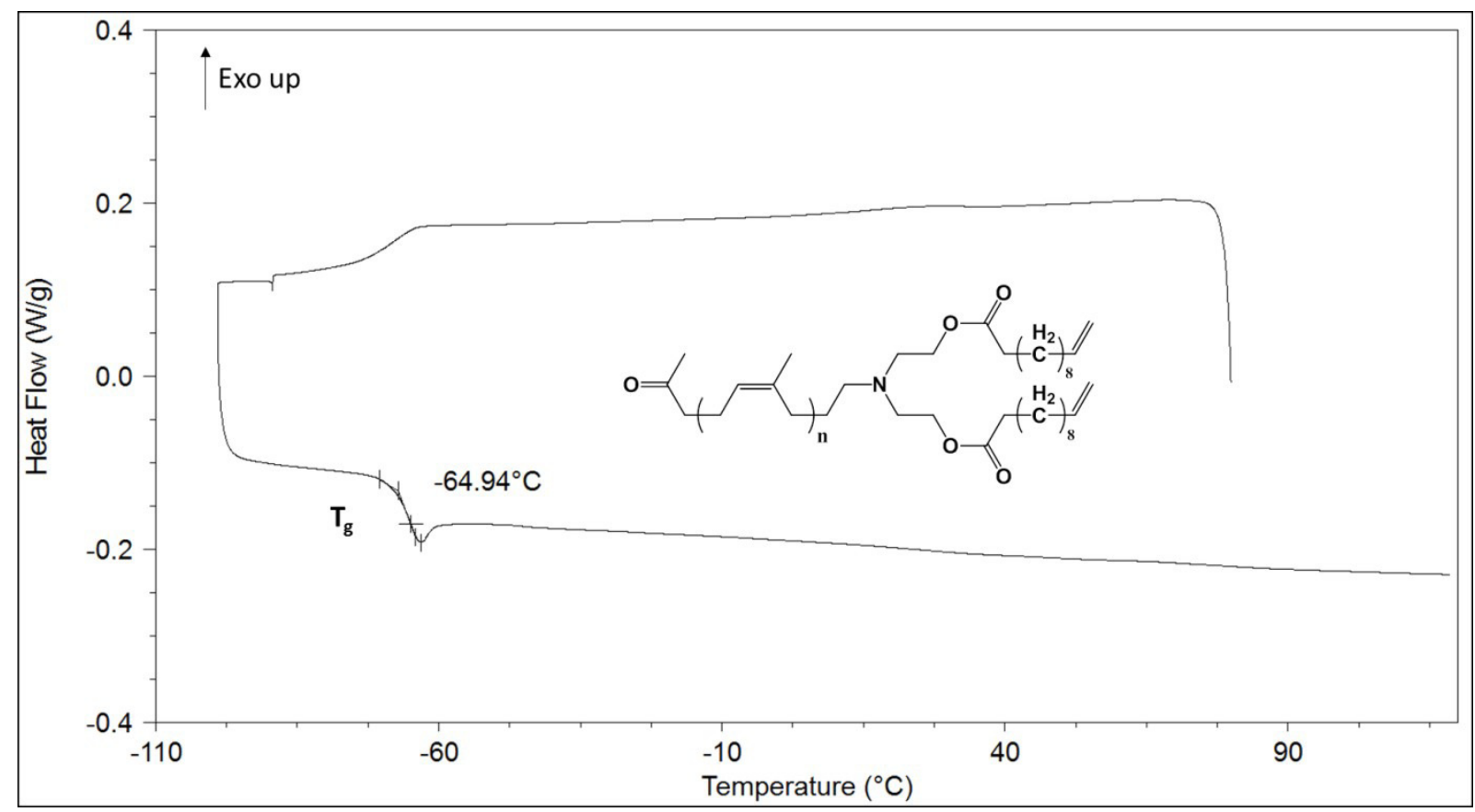

Figure S21: DSC thermogram of $\mathrm{PIDiC}_{11: 1}$

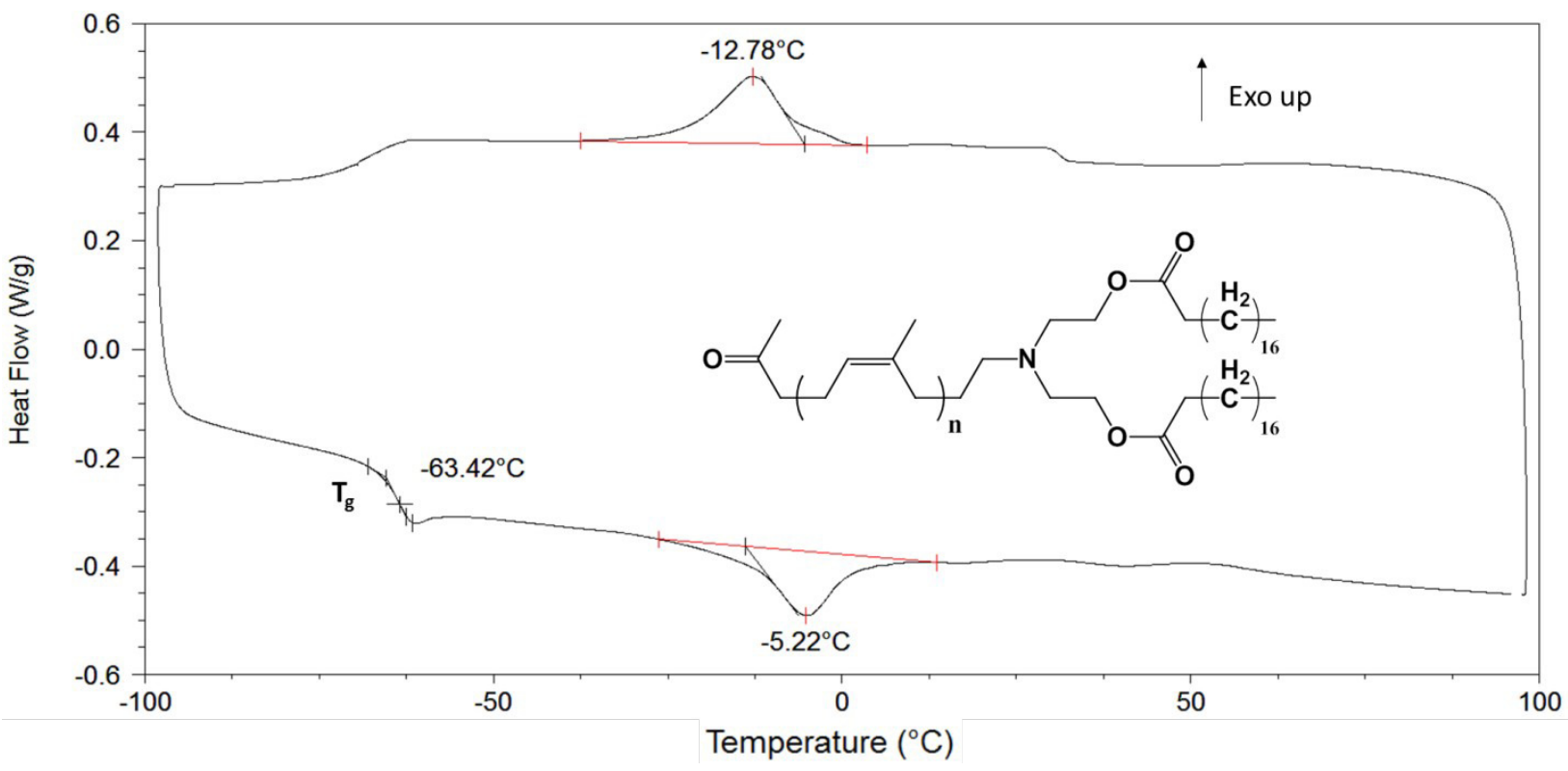

Figure S22: DSC thermogram of PIDiC ${ }_{19: 0}$ 


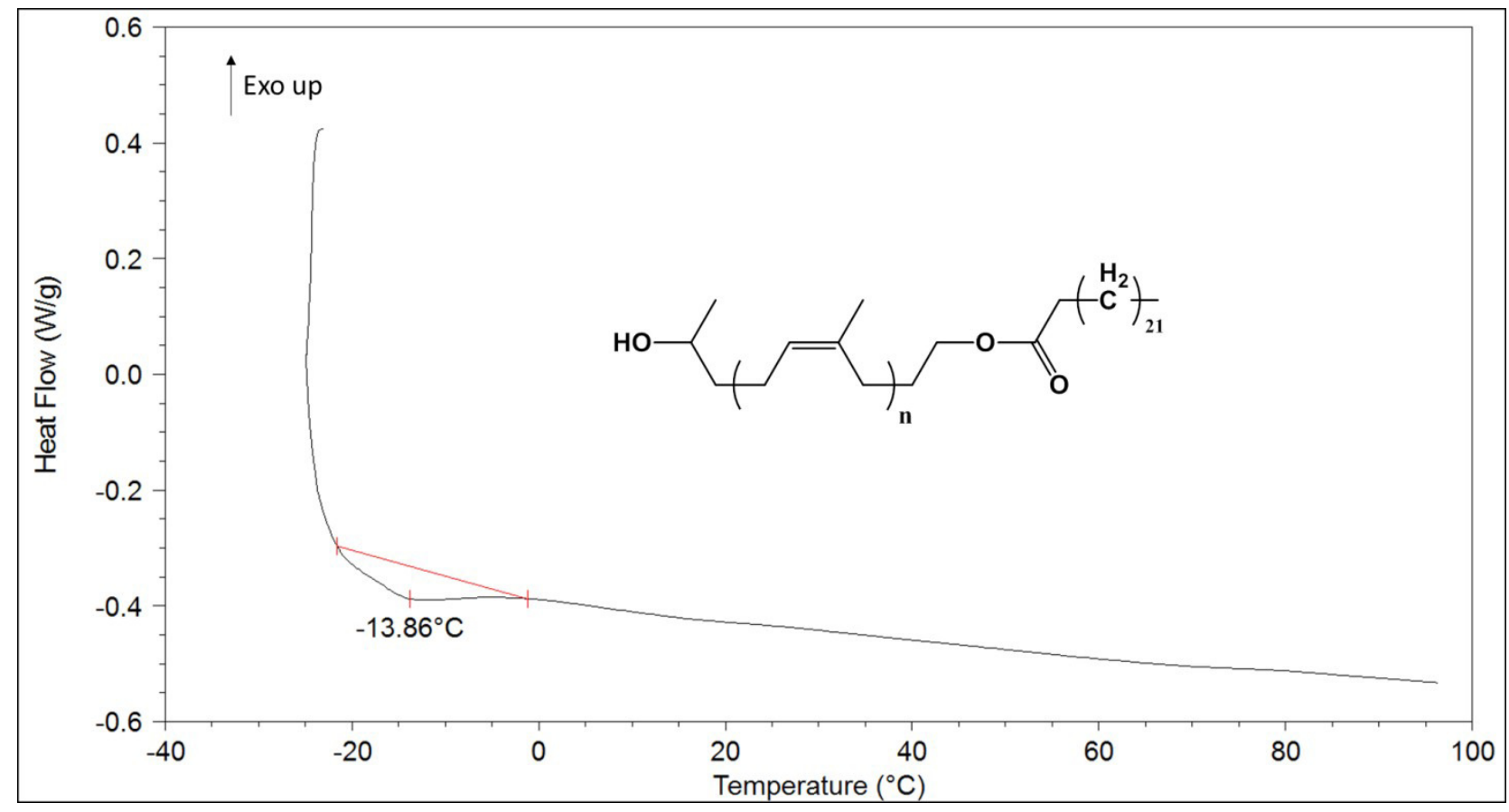

Figure S 23: DSC thermogram of a PIMono $\mathrm{C}_{24: 0} \mathrm{OH}$ after $8 \mathrm{~h}$ of isothermal crystallization at $\quad-25^{\circ} \mathrm{C}$

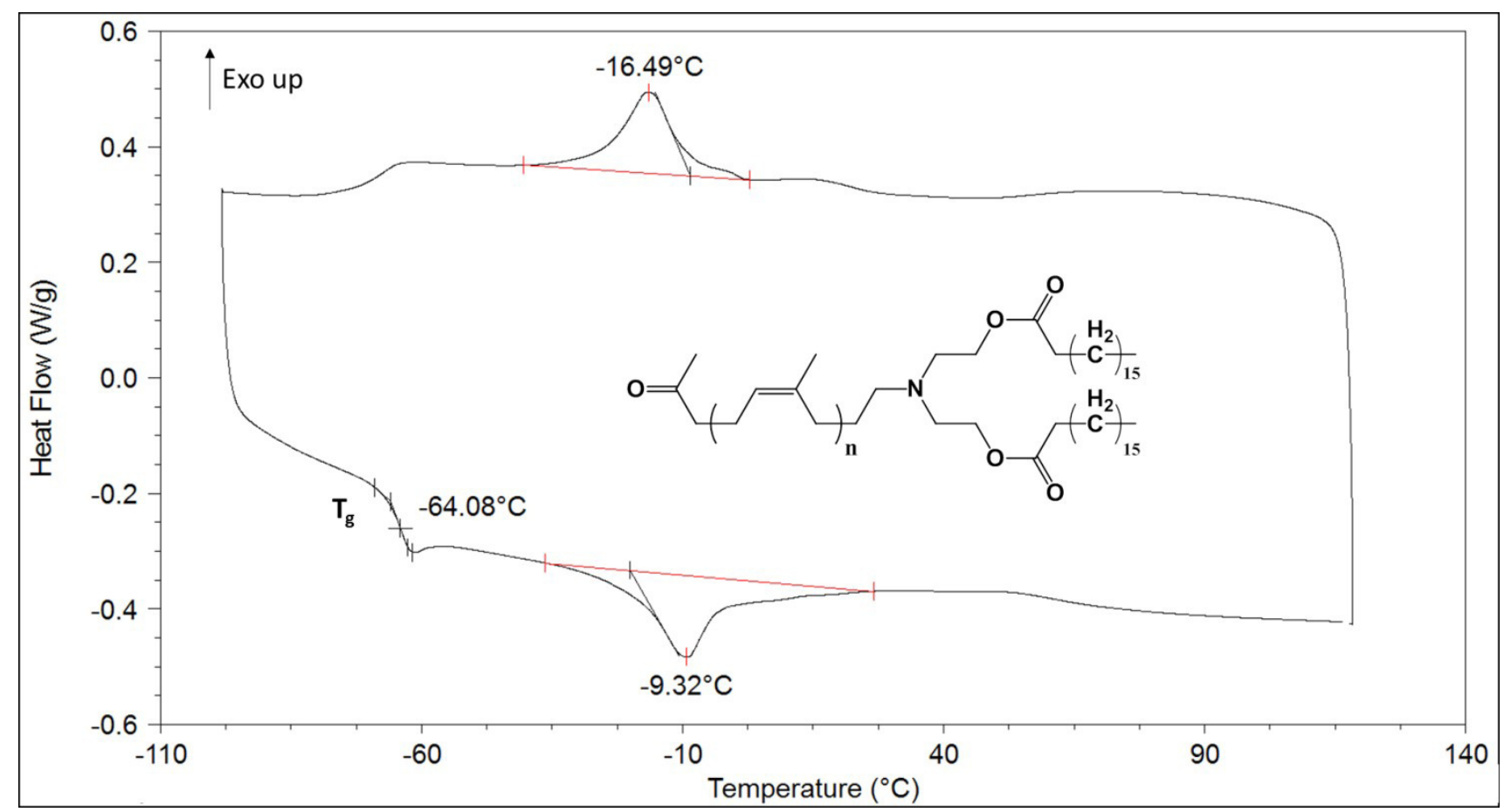

Figure S24: DSC thermogram of IRDiC $18: 0$ 


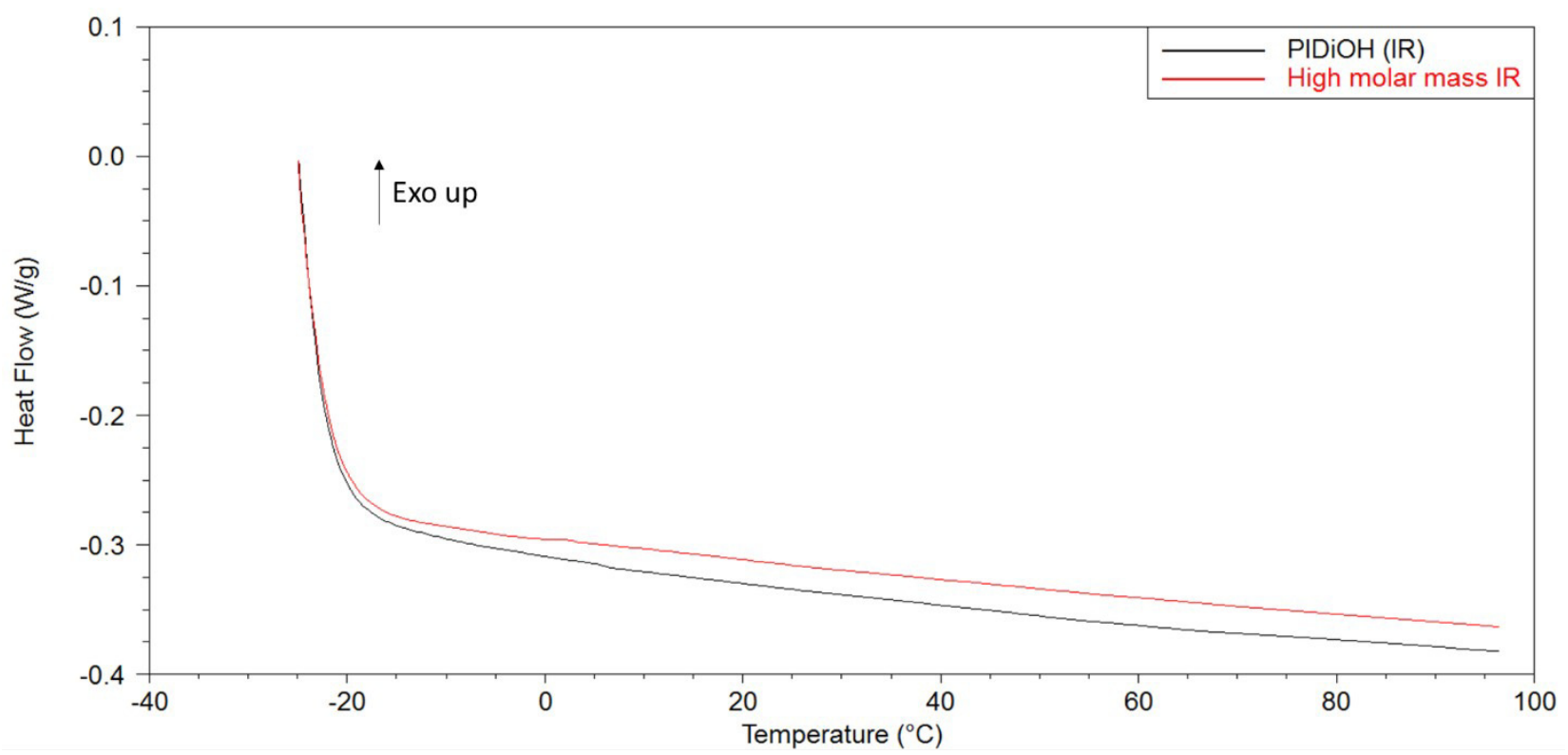

Figure S25: DSC thermograms of initial IR and IRDiOH after $8 \mathrm{~h}$ of isothermal crystallization at $-25^{\circ} \mathrm{C}$

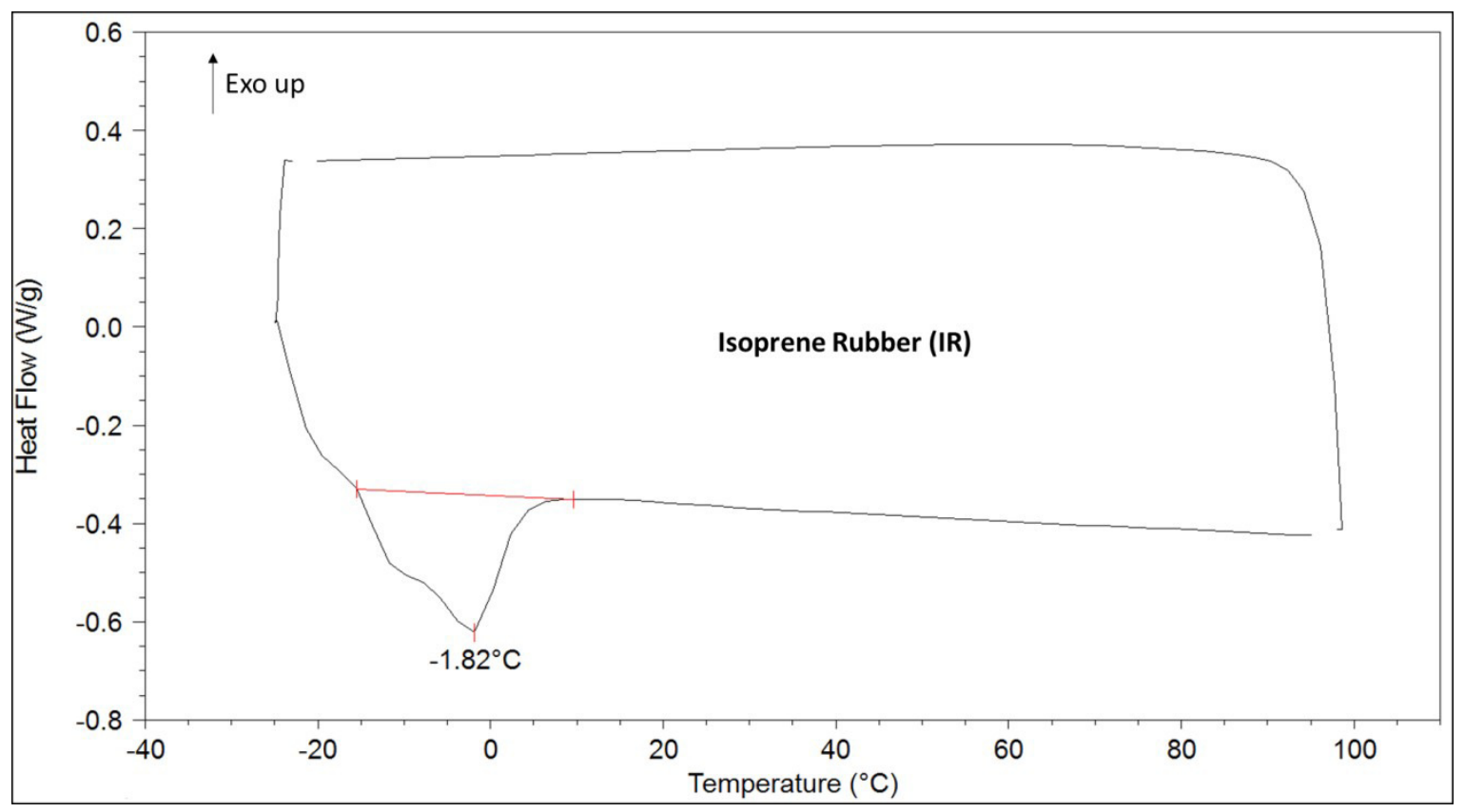

Figure S26: DSC thermogram of high molar mass IR after isothermal crystallization at $-25^{\circ} \mathrm{C}$ for $60 \mathrm{~h}$. 


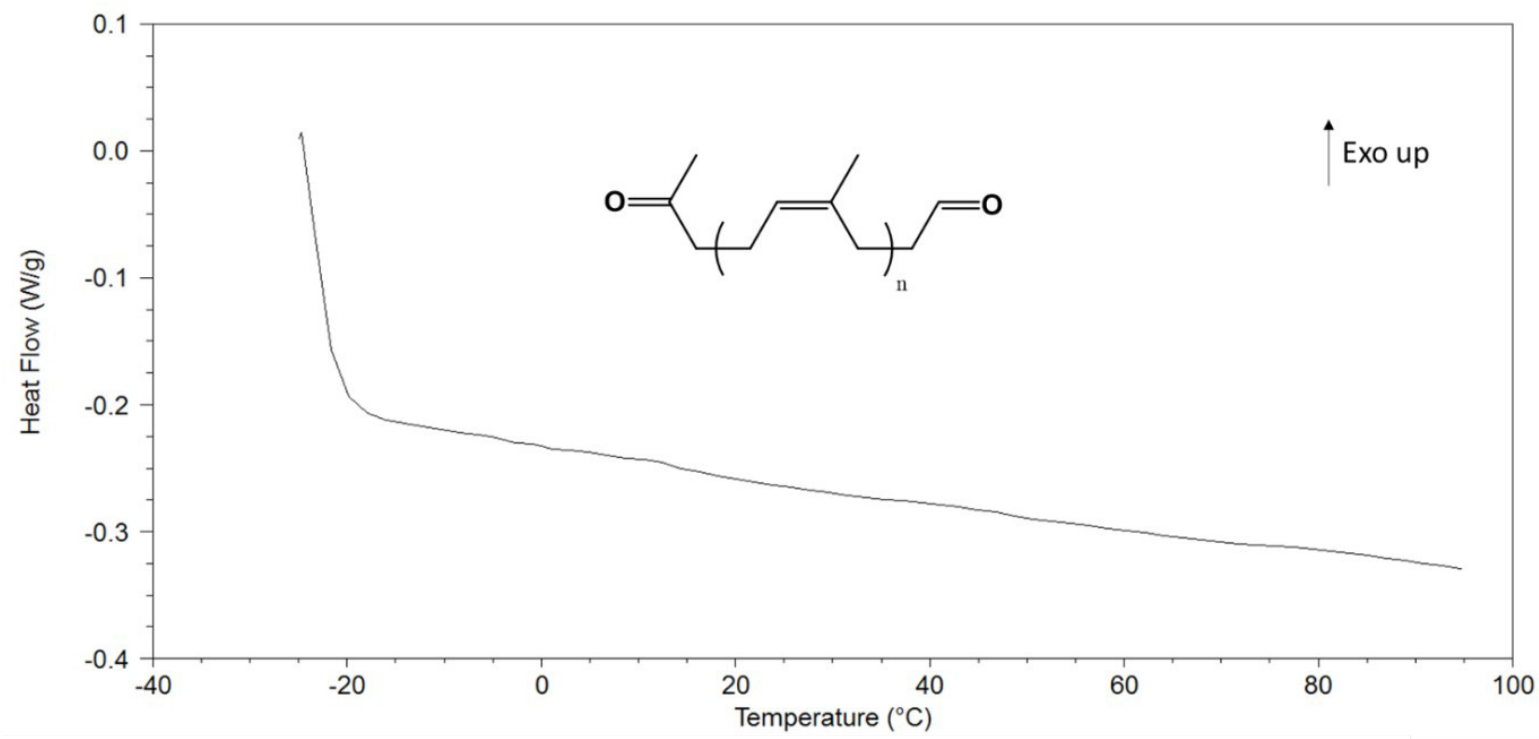

Figure S27: DSC thermogram of IRDeg after isothermal crystallization at $-25^{\circ} \mathrm{C}$ for $60 \mathrm{~h}$. 